
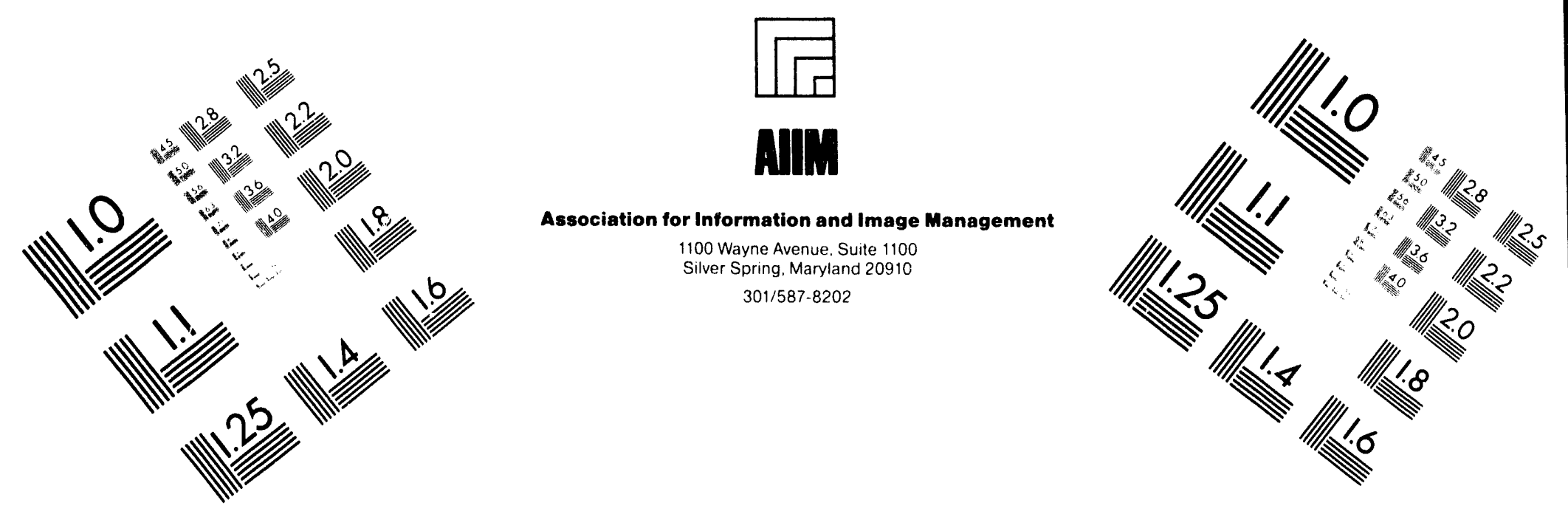

\title{
Centimeter
}

| Inches
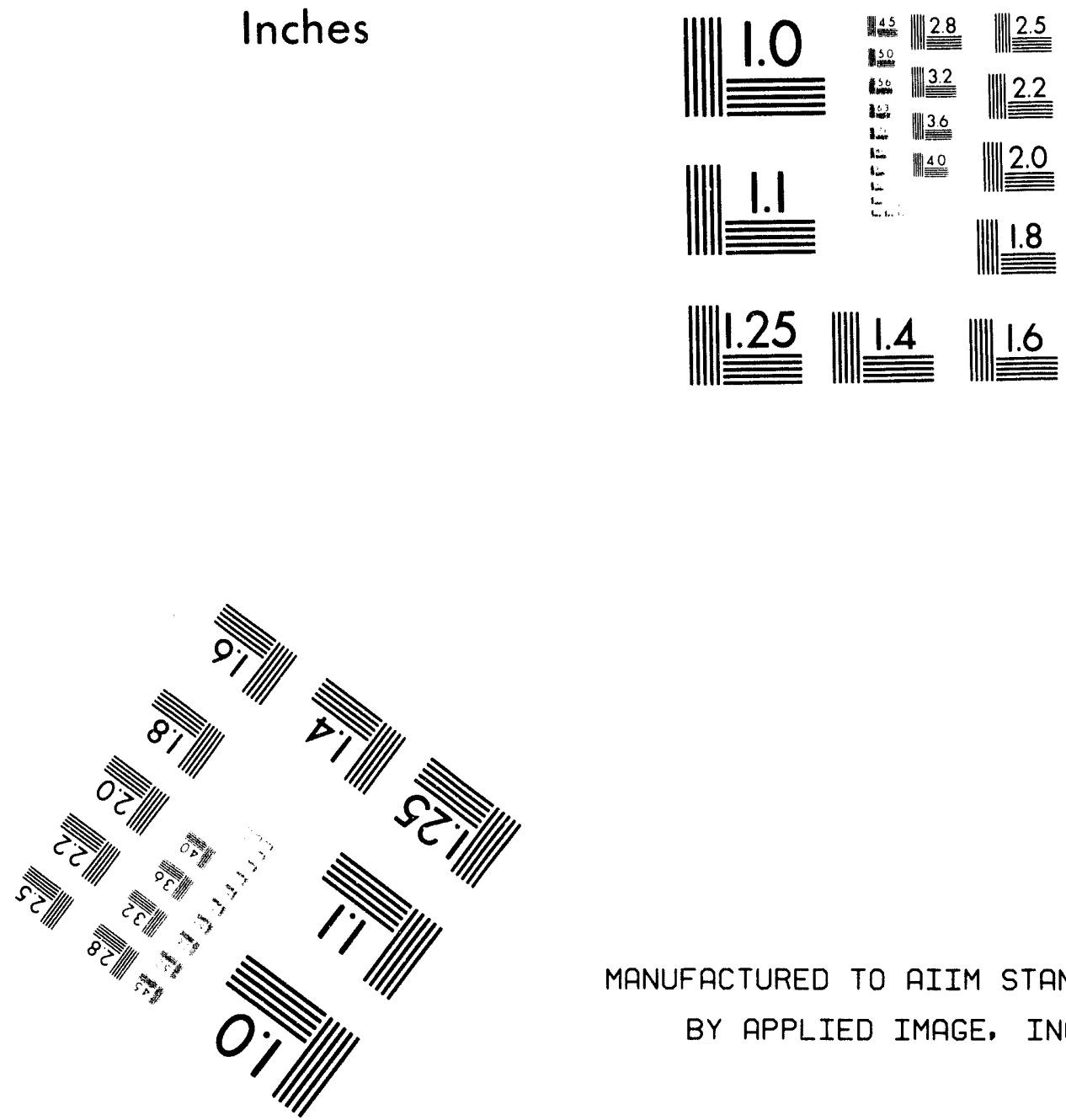

MANUFACTURED TO AIIM STANDARDS BY APPLIED IMAGE, INC.

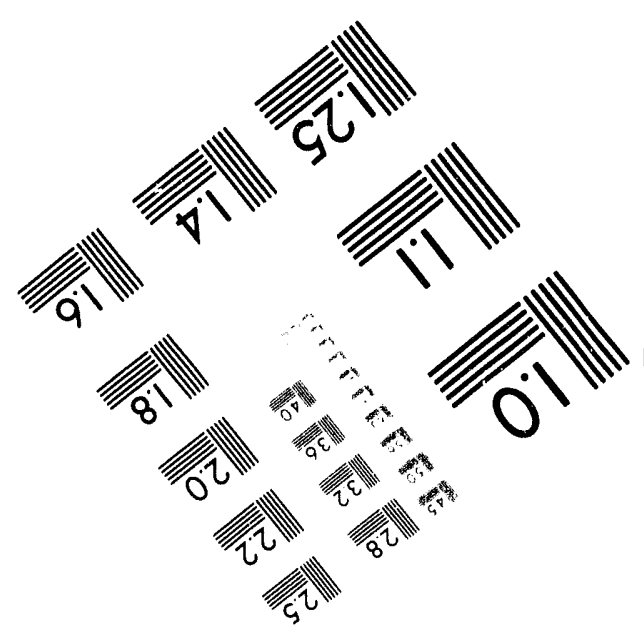



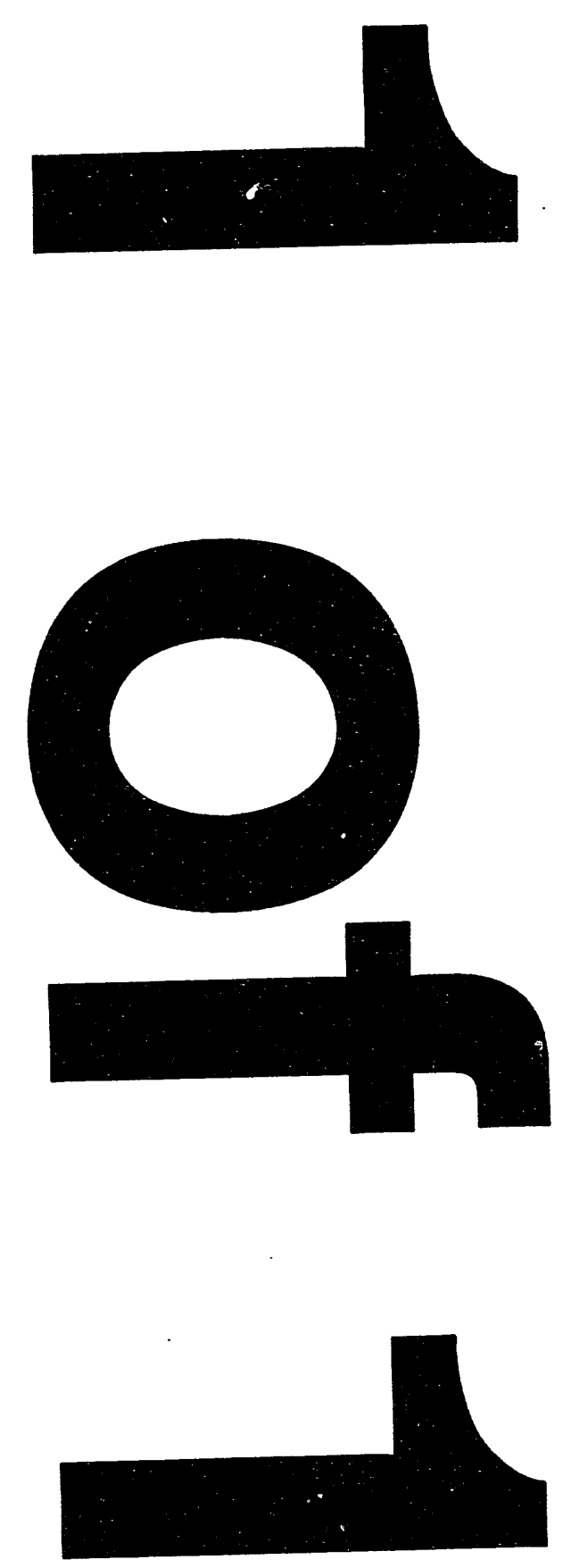
NUREG/CR-6252

PNL-9871

BSRC-800/94/014

\section{Lessons Learned From the Three Mile Island-Unit 2 Advisory Panel}

Manuscript Completed: June 1994

Date Published: August 1994

Prepared by

D. Lach, P. Bolton, N. Durbin/BSRC

R. Harty/PNL

Battelle Seattle Research Center

4000 NE 41st Street

Seattle, WA 98105

Pacific Northwest Laboratory

902 Battelle Boulevard

Richland, WA 99352

Prepared for

Division of Operating Reactor Support

Office of Nuclear Reactor Regulation

U.S. Nuclear Regulatory Commission

Washington, DC 20555-0001

NRC FIN B2525 


\begin{abstract}
In response to public concern about the cleanup of the Three Mile Island, Unit 2 (TMI-2) facility after an accident on March 28, 1979, involving a loss of reactor coolant and subsequent damage to the reactor fuel, twelve citizens were asked to serve on an independent Advisory Panel to consult with the Nuclear Regulatory Commission (NRC) on the decontamination and cleanup of the facility. The panel met 78 times over a period of thirteen years (November 12, 1980 - September 23, 1993), holding public meetings in the vicinity of TMI-2 (Harrisburg, Pennsylvania) and meeting regularly with NRC Commissioners in Washington, D.C.
\end{abstract}

Abstract
This report describes the results of a project designed to identify and describe the lessons learned from the Advisory Panel and place those lessons in the context of what we generally know about citizen advisory groups. A summary of the empirical literature on citizen advisory panels is followed by a brief history of the TMI-2 Advisory Panel. The body of the report contains the analysis of the lessons learned, preliminary conclusions about the effectiveness of the Panel, and implications for the NRC in the use of advisory panels. Data for the report include meeting transcripts and interviews with past and present Panel participants. 


\section{Table of Contents}

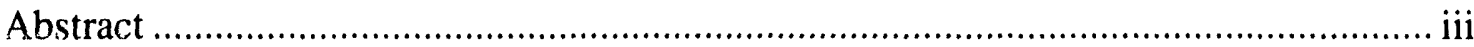

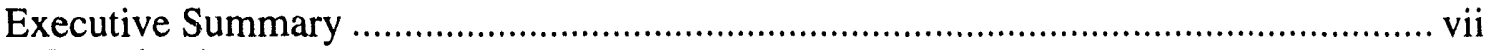

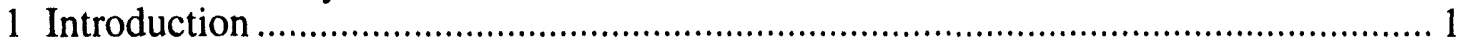

1.1 Methods for Data Collection ............................................................ 1

1.2 Review of Empirical Literature on Citizen Advisory Panels ....................... 3

2 A Brief History of the TMI-2 Advisory Panel ...................................................... 6

3 Lessons Learned from the TMI-2 Advisory Panel ................................................ 10

3.1 Panel Objectives ............................................................................... 10

3.1.1 Analysis of Panel Objectives ..................................................... 10

3.1.2 Summary of Lessons Learned about Panel Objectives ................ 12

3.2 Characteristics that Support İmplementation of Advisory Panels .............. 12

3.2.1 Analysis of Characteristics that Support Implementation of Advisory Panels ..................................................................... 12

3.2.2 Summary of Lessons Learned about Characteristics that Support Implementation of Advisory Panels ........................... 14

3.3 Panel Composition ................................................................................ 14

3.3.1 Analysis of Panel Composition ................................................... 14

3.3.2 Summary of Lessons Learned about Panel Composition ............. 16

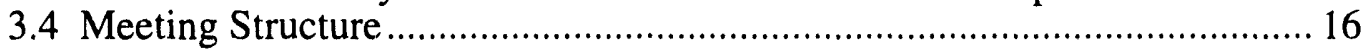

3.4.1 Speaking Rules................................................................ 17

3.4.2 Setting the Agenda ............................................................. 18

3.4.3 Meeting with the Commissioners ............................................ 18

3.4.4 Changes in the Meeting Structure ............................................ 19

3.4.5 Suggested Improvements for Meeting Structure ....................... 20

3.4.6 Summary of Lessons Learned about Meeting Structure ............... 21

3.5 Panel Influence on Cleanup Efforts ............................................................. 21

3.5.1 Analysis of Panel Influence on Cleanup Efforts ....................... 21

3.5.2 Summary of Lessons Learned about Panel Influence on the Cleanup .................................................................................. 22

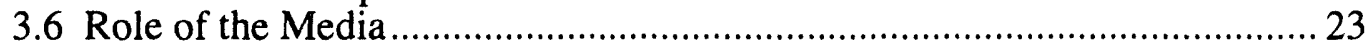

3.6.1 Analysis of the Role of the Media ............................................ 23

3.6.2 Summary of Lessons Learned About the Role of the Media ........ 24

3.7 Advisory Panel Longevity ....................................................................... 24

3.7.1 Analysis of Advisory Panel Longevity .................................... 24

3.7.2 Summary of Lessons Learned about Advisory Panel Longevity .. 26

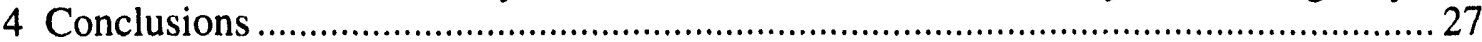

4.1 Effectiveness of TMI-2 Advisory Panel ................................................. 27

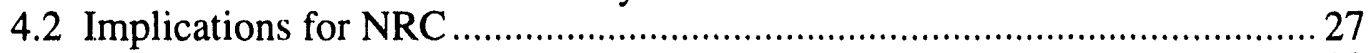

5 References

Appendix A

Panel meeting dates and transcript microfiche addresses ............................. 31

Appendix B

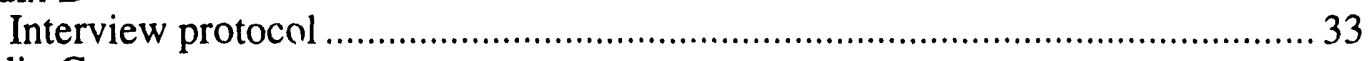

Appendix C

List Of Interviewees And Contact Documents .................................................. 36

Initial Contact Letter with Potential Study Participants......................................... 37

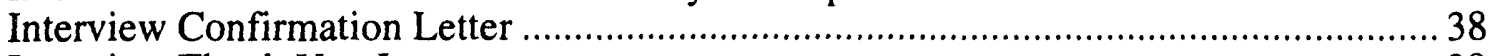

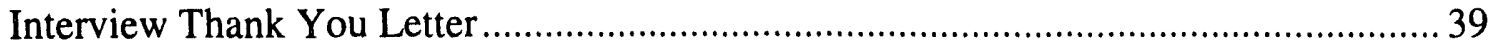

Table

Table 3.1 Characteristics that support implementation of advisory panels .................. 13 


\section{Executive Summary}

An accident at the Three Mile Island-Unit 2 facility (TMI-2) on March 28, 1979, involved a loss of reactor coolant and resulted in serious damage to the reactor fuel. In response to public concern about the cleanup of TMI-2 after this accident, twelve citizens, including scientists, elected officials, and lay people, were asked to serve on an independent panel to consult with the Nuclear Regulatory Commission (NRC) on the decontamination and cleanup of the TMI2 facility. The Advisory Panel for the Decontamination of the Three Mile Island, Unit 2 met for the first time on November 12, 1980, in Harrisburg, Pennsylvania. The Panel held 78 meetings over 13 years, meeting regularly with both the public and NRC Commissioners. The final meeting of the Advisory Panel was held September 23, 1993. By the end of 1993, TMI-2 had been placed in long-term storage, and many, but not all, participants believed that the general usefulness of the Panel was at a natural end.

Before any decision to terminate Panel activities had been made, NRC contracted with the Pacific Northwest Laboratory (PNL) and Human Affairs Research Centers (HARC) of Battelle to characterize participants' experiences with the Advisory Panel. Participants include all those individuals and organizations who attended the Panel meetings representing the agency, the licensee, the Panel, no,n-governmental organizations, and members of the public. The project was designed to identify and describe the lessons learned from the long-lived Advisory Panel and place those lessons in the context of what is generally known about citizen advisory groups.

Three methods were used to collect information for the analysis: a review of the relevant literature on citizen advisory panels; a review of selected Advisory Panel meeting transcripts; and interviews of selected Advisory Panel participants. Thirty-two transcripts were analyzed and 26 interviews conducted for the report. The ninety-minute interviews were held with past and present Advisory Panel participants including Panel members, NRC staff, licensee staff, general public, and media representatives.

The interview and meeting transcripts were analyzed to identify the types of issues and concerns raised by Panel participants over the life of the Panel. In addition, the literature on citizen advisory panels suggested several issues about advisory groups which needed to be considered in the analysis. Information from the transcript analyses and literature review was used to develop the list of areas that was closely analyzed for this report.

The areas of concern identified through the literature review and examination of meeting and interview transcripts were used to organize the information into a lessons-learned analysis. The lessons learned include the following:

\section{Panel Objectives}

- Original objectives were well known to all Panel participants and used effectively to keep Panel meetings on track.

- Participants believed that Panel objectives were met although there was concern that reduced public participation also reduced the ability of the Panel to represent the public.

- Participants perceived that implicit Panel objectives included reducing public anxiety about the accident and cleanup of TMI-2 and believed these objectives were met.

- Panel members were able to reduce growing antagonism and conflict between members of the public and other Panel participants by expanding the original objectives to include issues of great concern to the public.

2. Characteristics that Support Implementation of Advisory Panels 
- Successful advisory group implementation requires a high profile problem with a specific focus.

- Without an appropriate focus, an advisory panel is unlikely to attract quality participants or hold their attention for long.

- Maintaining a successful advisory group requires a continuing high public iriterest in the event or topic.

\section{Panel Composition}

- A range of expertise increased the capability of the Panel members to participate in technical and political discussions.

- Panel members educated both the public and each other across different areas of expertise and capability.

- Diverse perspectives and capabilities increased conflict among Panel participants. This conflict, however, appeared to contribute to the perception of the Panel as a credible and legitimate forum for discussion of the cleanup activities.

- The wide range of Panel members' perspectives also appeared to increase the credibility of the Panel with other participants and observers.

- Although some Panel members were unable to contribute directly during certain technical discussions, they did participate by providing additional perspectives to the issues under consideration.

\section{Meeting Structure}

- Consistently applied speaking rules created a perception of fairness among Panel participants.

- An informal atmosphere provided the appropriate flexibility for wide participation.
- Impersonal methods for meeting control maintained respect for individual perspectives.

- A mid-meeting public comment period increased the range of public response and reduced increasing tensions between citizens and panel members.

- Frequent, but controlled, periods for public participation increased the quality and quantity of input and reduced ongoing conflict over meeting procedures.

- Recommendations and reports to the NRC Commissioners were most often developed through informal consensus building among Panelists.

- Respondents believed that improvements could be made to the Advisory Panel by increasing resources for the Panel, increasing the technical aspects of the NRC Designated Official role, and reassessing how Panel members are selected.

- Term limits for Panel members did not appear feasible to most participants due to the complexity of cleanup issues.

5. Panel Influence on the Cleanup

- The most crucial Panel influence on cleanup activities was the increased public scrutiny of both NRC and licensee decisions and activities.

- The Panel facilitated communication with the public for both the NRC and the licensee. This communication helped sensitize the agency and the licensee to public concerns.

- The level of technical influence on cleanup activities was modest and, in any case, difficult to untangle from other pressures put on the licensee. Most respondents agree, however, 
that Panel and public questions expanded the range of alternatives considered by the NRC and the licensee.

\section{Role of the Media}

- Local media covered the Advisory Panel meetings throughout the years. In the early years, front page coverage of meetings was common. During later years, stories about the meetings moved to back pages with other, less controversial, news.

- Media coverage disseminated cleanup information to a wider audience than was reached through the Panel meetings.

- Media coverage encouraged high quality presentations about the cleanup.

- Some participants believe that media coverage provided opportunities for grandstanding and irresponsible claim-making to wide audiences.

- Media coverage may have reinforced the significance of Panel activities to Panel members and encouraged their continued participation.

\section{Panel Longevity}

- Many participants continued with the Panel in spite of initial concerns about its efficacy because it was the only forum available for participating in discussions about the cleanup.

- The longevity of the Advisory Panel served to smooth over divergent views of Panel participants, allowed enough time for individuals to learn about the complicated technical issues involved in the cleanup, and created an almost universal perception that the Panel was an effective communication forum.
- Although interpersonal trust between Panel participants was generally quite high, this trust has not typically been translated into increased trust of the institutions or organizations that other participants represented.

- All past and present Panel members expressed surprise that the Panel survived for 13 years. Even those Panel members who believed the Panel should continue thought the Panel had only a few issues left to address.

Each of the above lessons is discussed fully in the report, using quotes and examples from the interviews and transcripts to provide details and corroboration of the analyses. The information provided in this report is based on the reported perceptions of Panel participants, the review of the transcripts, and the literature review. It is not intended as a representation of the "true" Panel experience. Instead, it is meant to evoke the Panel experiences of a variety of individuals over a long period of time and place the experience within a general context of what is known about citizen advisory panels.

While the purpose of this report is not to assess the effectiveness of the Advisory Panel, the respondents' interviews and transcript analyses provide some evidence about perceptions of the Panel's effectiveness. In general, the Advisory Panel was perceived by interviewed participants and observers as a success in meeting its objective of opening a communication channel between the public and the NRC. Although the Panel was a moderately expensive resource decision for the NRC, it is probable that pressure on the NRC to support some method for individuals and groups to participate in the cleanup discussions would have continued to mount in the months following the accident. Instead, the implementation and continued support for an Advisory Panel, which was considered legitimate by most participants, defused that pressure so that 


\section{Executive Summary}

NRC, licensee, and public attention could be turned to the technical aspects of the cleanup. 


\section{Introduction}

The U.S. Nuclear Regulatory Commission (NRC) contracted with Pacific Northwest Laboratory (PNL) ${ }^{1}$ and Battelle's Human Affairs Research Centers (HARC) to characterize participants' experiences with the Citizens' Advisory Panel for the Decontamination of Three Mile Island Unit 2 (the Advisory Panel), instituted by the NRC after the accident at the Three Mile Island Unit 2 reactor (TMI-2). The purpose of the project was to identify and describe the lessons learned from the Advisory Panel and place those lessons in the context of what we generally know about citizen advisory groups.

This document summarizes the results of the project. After describing the methods used to collect and analyze the data, the empirical literature about citizen advisory panels is reviewed and background information about the panel is provided. The main body of the report contains the analysis of the lessons learned about the TMI-2 Advisory Panel. In the conclusion of the report, effectiveness of the Advisory Panel and implications for the NRC in the use of advisory panels are addressed.

After the report was drafted, the NRC solicited both internal and external reviews. The draft report was also placed in the Harrisburg, Pennsylvania, and Washington, D.C., public document rooms. NRC reviewers included B. Grimes, J. Hoyle, W. Travers, L. Thonus, F. Cameron, M. Masnik, F. Young, and P. Kleene. Panel members J.

Luetzelschwab, T. Smithgall, K. Miller, G. Robinson, and A. Morris also reviewed the draft report. Outside reviewers of the draft report included E. Epstein, F.

Standerfer, and R. Long. Providing comments to the NRC does not constitute an endorsement of the report by the reviewer. Many valuable comments, however, were received from the reviewers and are incorporated into the final version of the report.

1 Pacific Northwest Laboratory is operated for the U.S. Department of Energy by Battelle Memorial Institute under Contract DE-ACO6-76RLO 1830.

\subsection{Methods for Data Collection}

The objectives of the project required information about the Advisory Panel from many different perspectives throughout the life of the Panel. Several sources were used to gather the information. In addition to reviewing the relevant literature on citizen advisory panels, we reviewed a sample of the Panel meeting transcripts and interviewed a range of Panel participants. We talked with both current and past Panel participants including Panel members, NRC staff, licensee staff, media, and citizen activist groups. In general, collecting data from multiple sources allowed us to corroborate interpretations of the data. In addition, each of the three methods used to collect data for the analysis also provides a unique type of information:

(1) The review of relevant literature on citizen advisory panels was used to identify issues that needed to be addressed in the interviews as well as to place the results of the data analysis in a larger context of what is known about advisory panels.

(2) The analysis of selected Advisory Panel meeting transcripts tracked the history of the Advisory Panel, noted issues that were addressed by Panel members, identified changes in the meeting structure, and developed a partial understanding of the Panel participants and their relationships with each other. This analysis was used to develop the interview questionnaire, provide background information during the interviews, and corroborate interview data.

(3) The interviews with selected Advisory Panel participants solicited the perceptions and memories of Panel experiences from a range of past and present participants. The raw data of the interviews were used in the final analysis, along with information from the transcript analysis and literature review, to describe 
the lessons learned from the TMI-2 Advisory Panel experience

Each of these methods is described more fully below.

Relevant literature (1975 to date) in sociology, psychology, planning, public administration, political science, natural science, and law was reviewed for information about the use of citizen advisory panels. This information was collected to develop a context for the analysis of the lessons learned from the TMI-2 Advisory Panel as well as to provide insight in developing the interview questionnaire. The literature review is presented in Section 1.2.

A complete transcript of each Advisory Panel meeting was prepared by a court reporter who recorded and transcribed the meetings. A total of 68 transcripts was available for review. ${ }^{2}$ In view of the large number of meetings held by the Panel over the years, a sample of these transcripts was selected for review and analysis. Every other meeting transcript for meetings held between 1980 and 1986 was selected for review. For the meetings held between 1987 and 1992, every third meeting transcript was selected and analyzed. All transcripts of Advisory Panel meetings with the Commissioners were reviewed. This sampling scheme was used to ensure that transcripts from a range of meetings throughout the life of the Pancl was reviewed. Thirty-two transcripts were reviewed for this report.

Each selected transcript was read and coded. An analysis was prepared for each coded transcript that identified Panel objectives, topics or issues discussed, meeting mechanics, relationships between various parties, and other issues specific to the meeting. This information was then examined to identify any patterns or themes that occurred from meeting to meeting or changed over the years. The

\footnotetext{
2 Appendix $\mathrm{A}$ is a listing of the Panel meeting dates and U.S. Nuclear Regulatory Commission microfiche address of each available transcript.
}

transcript analysis was used to develop the interview questionnaire, provide background information during the interviews, and corroborate data collected through the interviews with Panel participants.

Interviews were conducted with selected past and present Advisory Panel participants, including Panel members, NRC staff, licensee staff, general public, and media representatives. Potential interviewees received a letter from the NRC Designated Federal Official (DFO) approximately ten days before they were contacted by the study team. The letter described the purpose of the project and explained how the interviews would be conducted. Individuals were then contacted to secure their agreement to be interviewed and to schedule a convenient time for each interview. Every participant who was contacted agreed to be interviewed for this report. A follow-up letter was then sent to everyone who agreed to participate, confirming the time and place of the interview. Each participant received a thank-you letter after interviews were completed. Copies of the form letters are included in Appendix C.

Twenty-six individuals were interviewed for this analysis. Interviews were conducted with both past and current Advisory Panel participants, including twelve Advisory Panel members, five NRC staff, three licensee staff, five members of the public, and one media representative. The interviewees and their affiliations are listed in Appendix C. Most of the interviews were conducted in person. Three interviews were conducted over the phone because the respondents were unavailable during the time the study team was on the East Coast interviewing Panel participants. Each interview took about 90 minutes to complete and consisted of a series of semi-structured questions. The interview protocol is attached in Appendix B.

The study team decided not to tape-record interviews. Transcribing taped interviews 
is very costly, and we were able to capture the amount of detail needed for this analysis through writing down participants' responses as the interviews were conducted. When possible, each interview was conducted by two researchers although several interviews were conducted by only one member of the study team. When two researchers were available for the interview, one researcher conducted the interview while the other researcher wrote down the responses. When only one researcher was available for the interview, the researcher botis conducted the interview and wrote down responses. Participants' responses were recorded on the interview protocol and later transferred to a computer database for analysis. A brief analysis of the completed interview protocols suggests that both the one- and twoperson methods of recording responses provided adequate data for this analysis.

Data from the interviews were entered into a database that allowed manipulation of the information. The data were then sorted by topic and by respondent type (e.g., "Panel member"). Patterns in responses were identified and then compared across respondent type. These patterns and themes were used to develop the lessons learned for this report. Quotes from the interviews and transcripts are used to corroborate the interpretation of the data.

The interviews and analysis for this report were undertaken and completed while the Advisory Panel was still in existence. This analysis was not intended to evaluate the effectiveness of the Advisory Panel or determine whether the Panel should continue. Instead, the purpose of the analysis was to determine lessons learned from the long-lived Advisory Panel from which others may benefit. Panel participants who were interviewed for this report provided input in the belief that the Panel was continuing at least for some additional months.

\subsection{Review of Empirical Literature on Citizen Advisory Panels}

Much has been written over the last twenty years about public participation in general and, more specifically, how citizen advisory panels assist organizations in decision making. Most of this work has been either descriptive or prescriptive in nature: the description of one or a few case studies of advisory panels or a list of professional prescriptions for "how to do" citizen advisory panels. While informative, this descriptive and prescriptive literature is specific only to the context or situation within which it was captured and analyzed. Because the reports are so context-bound and we are unsure what role(s) the context or situation plays in advisory panel operation, the literature contains little information that can be generalized with confidence to other situations. A review of the small body of empirical literature specific to citizen advisory panels, however, does provide details on what we currently know about such panels. Information from this review was used to develop the interview questionnaire as well as to analyze the results of the interviews.

The reviewed literature was taken from a wide range of disciplines, including sociology, psychology, political science, law, planning, and natural resources. Therefore, the theoretical perspectives on panels and the specific application to substantive issues varies across the literature. The findings reported here do suggest some consistency across disciplines and applications. The analysis of the reviewed literature is organized into four areas and briefly reviewed below:

(1) objectives of advisory panels

(2) outcomes of advisory panels

(3) structural variables

(4) limitations of advisory panels. 
A number of objectives for citizen advisory panels have been observed and measured across many advisory panel projects. When met, these advisory panel general expectations can serve, to some degree, the needs of both citizens and decision makers. Citizen-oriented objectives for advisory panels include identifying and presenting citizen values and inputs to local, state, and federal decision makers (Carpenter and Kennedy 1988; Robin and Hannah 1984) and increasing participation in decisionmaking processes (Doerksen and Pierce 1975; Dunn 1975). Objectives oriented more to decision makers include securing cooperation with or improving acceptability of official decisions (Bisogni, Lemley, and Fessenden-Raden 1983; Konnheim 1988) and generating new ideas or alternatives for problem solving (Robin and Hannah 1984). Advisory panel objectives that appear to serve equally the interests of both citizens and decision makers include educating community and panel members about issues specific to the problems, as well as procedures for participating in organizational decision making (Bisogni, Lemley, and Fessenden-Raden 1983; Carpenter and Kennedy 1988) and expanding the reach and/or breadth of individuals and programs through community and agency awareness and involvement in the advisory process (Christopoulo 1974; Robin and Hannah 1984).

While most outcomes of citizen advisory panels are specific to the individual project, a more general set of panel outcomes has also been documented. In general, advisory panel participants (both panel members and others involved in panel activities) report high levels of satisfaction with the outcomes of projects (Carpenter and Kennedy 1988; Desario and Langton 1987; Konnheim 1988). Participants in citizen advisory panels also report increased satisfaction with social institutions with which they have not been directly involved (Christopoulo 1974; Desario and Langton 1987; Reinking and Berkholz 1982). For example,
Christopoulo (1974) reports that citizen advisory panel participants undergo positive changes in attitudes toward government in general. Elected and nonelected officials who participate in citizen advisory panels or receive input from panels, however, report mixed opinions about the value or importance of panel recommendations and may even resist input from panels (Robin and Hannah 1984; Morgan and England 1983; Shanley 1976).

Several studies have examined how physical and procedural arrangements influence the perceived success or effectiveness of advisory panels. The most effective panel structure appears to be one with a balanced and independent membership, adequate resources, a strong chair, and full support from the sponsoring agency (Ashford 1984; Landre and Knuth 1992; Michels 1987; Shanley 1986). In addition, panels with a high percentage of professional members, access to a variety of information, and contact with diverse groups and individuals appear to have a high degree of internal control or perceived independence (as opposed to external control by the sponsoring agency). Internal control appears to increase the legitimacy of the panel with both participants and observers (HIannah and Lewis 1982; Robin and Hannah 1984). Panels with well-defined and widely accepted objectives tend to have higher levels of productivity than panels that struggle over objectives. Established objectives, however, appear to be only weakly connected to overall panel impact (Pearce and Rosener 1985). Finally, members of the public who do not participate directly in citizen panels express their general support for this decision-making method. The methods most preferred by the general public include decisions made by topical experts (e.g., an epidemiologist helping make decisions about reducing the spread of disease), groups of citizens, and administrators with expert experience. The least preferred methods include decisions made by state legislators, 
interest groups, and political parties (Doerksen and Pierce 1975).

\begin{abstract}
Although there appear to be many advantages to using citizen advisory panels in public decision making, the literature also points out limitations of the method. There is evidence that participants on advisory panels do not consistently reflect the average view of the public (Beatty and Pierce 1976; Priscoli 1983; Redburn, Buss, Foster, and Binning 1980). In fact, citizen advisory panels may fail to reach the individuals most in conflict with the sponsoring agency because these individuals are so disenfranchised they are unwilling or unable to participate (Christopoulo 1974). Lay members of panels are often at a disadvantage with respect to the scientific and technical issues that face many advisory panels (Krimsky 1984; Nelkin 1984). Thus, to be effective participants, lay panel members often need a great deal of time to learn enough about the issues. There also appears to be a constant tension in panel-sponsoring agencies between the desire to incorporate citizen participation into decision making and the more pragmatic practice and consequence of such participation (Nelkin 1984; Peterson 1984). These tensions include, as discussed above, a reluctance of some decision makers to accept the public input they solicited as well as lapses in communication and cooperation as attempts are made to integrate an advisory panel (and its input) within an alleady existing organization (Shanley 1976).
\end{abstract}




\section{A Brief History of the TMI-2 Advisory Panel}

Three Mile Island-Unit 2 (TMI-2) is a nuclear power reactor located on the banks of the Susquehanna River in Dauphin County, Pennsylvania, just south of Harrisburg. TMI-2 is a pressurized water reactor with a Babcock and Wilcox (B\&W) nuclear steam-supply system, which was designed to generate $890 \mathrm{MW}$ (megawatts) of electric power (2770 MW thermal). Metropolitan Edison Company, Jersey Central Power and Light Compariy, and Pennsylvania Electric Company were holders of the original license for the facility at TMI-2. 3

Between issuance of its operating license on February 8, 1978, and March 28, 1979, TMI-2 operated about 95 effective fullpower days. Operation ceased on March 28,1979 , after an incident occurred that involved a loss of reactor coolant and resulted in serious damage to the reactor fuel. When coolant was restored, radioactive contamination was distributed throughout the reactor coolant system and into the reactor building basement. Exposed surfaces and equipment in the reactor building and the auxiliary and fuel-handling buildings were contaminated with radioactive material contained in the water and steam that escaped from the reactor coolant system. Releases of radioactive material into the atmosphere outside of the facility occurred at the time of the accident. Additional releases occurred during the next several weeks as a consequence of controlled venting of the atmosphere in the reactor containment building.

${ }^{3}$ After the accident at TMI-2, the NRC issued an order on July 20,1979, which suspended the authority of the licensee to operate the facility and required that the licensee maintain the facility in a shut-down condition in accordance with approved operating and contingency procedures. Although its authority to operate the facility was suspended, the licensee retained an operating license. After the accident, GPU, the holding company for the three original licensee holders, formed a new corporation, GPU Nuclear Corporation (GPUN), and the license was transferred to that organization. In September 1993, the NRC issued a "possession only" license to GPUN for the TMI2 facility.
Since the accident, water released into the facility has been removed, extensively processed (to remove radionuclides), and evaporated. In addition to removing the contaminated water, cleanup activities included decontamination of much of the auxiliary and fuel-handling buildings as well as the reactor containment building. Approximately $99 \%$ of the fuel has been removed from the reactor vessel and the remainder of the facility. On August 16, 1988 , GPUN proposed placing the facility in a storage mode after the completion of the defueling process to allow decay of the radionuclides remaining in the facility. Workers would thus be exposed to lower levels of radioactivity during future decontamination and decommissioning of the facility. This storage mode, during which the facility is monitored by GPUN, is referred to as "post-defueling monitored storage" (PDMS). Following an in-depth review, the NRC approved the GPUN's request for post-defueling monitored storage on December 28, 1993.

The accident at TMI-2 had a measurable impact on the social and psychological well-being of individuals and groups in the area around TMI, although these impacts appear to have diminished over time (Hughey and Sundstrom 1988; Sills, Wolf, and Shelanshi 1982). Seventeen months after the accident at TMI-2, 30$50 \%$ of the population within a 25 -mile radius around TMI reported heightened concerns about the occurrence of another event. The majority of respondents in the survey also reported that TMI remained one of their greatest concerns and doubted their own coping abilities in dealing with any future problems at the facility (Sorenson, et al. 1987).

The "Advisory Panel for the Decontamination of Three Mile Island, Unit 2," hereafter referred to as the Advisory Panel or Panel, was established by the NRC under the Federal Advisory Committee Act (FACA) as amended (Public Law 92-463, 5 U.S.C., App.). This independent advisory panel was set up "for the purpose of obtaining input and views from the residents of the Three 
Mile Island area and affording Pennsylvania government officials an opportunity to participate in the Commission's decisional process regarding cleanup plans for the facility. The Panel will consider the comments expressed by the local residents, and make recommendations to the Commission" (Hoyle 1980a). The Advisory Panel met for the first time on November 12, 1980, in Harrisburg, Pennsylvania.

Administration of the Advisory Prnel was desigred to comply with the requirernents of FACA. Meetings of the Panel, for example, were required to be held at a reasonable time and in a place reasonably accessible to the public. Members of the public were also permitted to file written statements regarding any matter discussed at the Panel meetings and were permitted to speak at meetings in accordance with procedures established by the Panel. Notice of each meeting was published in the Federal Register at least 15 days before the meeting date and a press release was issued to notify the public of the date, time, location, and proposed agenda of the meeting. FACA required the Nuclear Regulatory Commission (NRC) to designate an employee of the Commission to coordinate and oversee the Panel operations. The Designated Federal Official (DFO) was responsible for facilitating the convening of each meeting, establishing the agenda with the Panel Chairman, filing the notice with the Federal Register, ensuring that minutes or transcripts of the meeting were prepared and available for public review, and collecting information required for annual reports about the Panel's activities. These requirements are laid out in full in the NRC Rules and Regulations, Title 10, Chapter 1, Part 7 of the Code of Federal Regulations - Energy.

FACA requires that Panel memberships be "fairly balanced in terms of the points of view represented and the functions to be performed." In considering individuals for original Panel membership, the NRC attempted to include a cross-section of individuals directly affected, interested, or qualified to serve on the Panel. Panel members served independently to advise and consult with the Commission on major activities involving the decontamination and cleanup of the TMI2 facility. The twelve original Panel members included local elected officials (John Minnich, County Commissioner of Dauphin County, PA.; Art Morris, Mayor of Lancaster, PA.; and Robert Reid, Mayor of Middletown, PA.), scientists (Tom Cochran of the Natural Resources Defense Council; Henry Wagner of Johns Hopkins University; Nunzio "Joe" Palladino of Pennsylvania State University), representatives of state agencies (Arnold Muller, Pennsylvania Department of Health; Clifford Jones, Pennsylvania Department of Environmental Resources; and Dewitt Smith, Jr., Pennsylvania Emergency Management Agency), and members of the general public (Ann Trunk, member of the President's Commission on the Accident at TMI [The Kemeny Commission]; Joel Roth, former Chair of Three Mile Island Alert [TMIA]; and Jean Kohr, attorney representing the Susquehanna Valley Alliance).

Panel membership was relatively stable over the life of the Panel, with three original members serving the entire period from 1980 to 1993 (Trunk, Roth, and Morris). There were a few notable turnovers over the years: Dr. Palladino left the Panel when he became Chairman of the Nuclear Regulatory Commission. After John Minnich, the original Advisory Panel Chairman, left the Panel in late 1983, Art Morris, then-mayor of Lancaster, took on the role of Chairman. Morris was Chairman of the Advisory Panel through the final meeting more than ten years later. Additional Panel members over the years included Mr. Joe DiNunno, Mr. Thomas Gerusky, Mr. John Luetzelschwab, Ms. Elizabeth Marshall, Mr. Kenneth Miller, Mr. Frederick Rice, Dr. Gordon Robinson, Dr. Neil Wald, and Mr. Thomas Smithgall.

Panel members were asked to serve without compensation other than travel 
costs. This issue became a contentious matter over the years and is discussed in more detail below. However, even with voluntary service, a quorum was present at every meeting of the Panel. The Panel was originally scheduled to meet at least twice each year. ${ }^{4}$ During the early years, however, they met much more often than twice a year. Panel members traveled to Washington, D.C., at least once each year to meet with the Commissioners and provide a report on current Panel activities.

Although Panel members were the official participants in the Advisory Panel, many other individuals and groups contributed to the effectiveness of the Panel. For the purpose of this report, all those individuals who attended and participated in Panel meetings will be referred to as "participants." Panel participants include Panel members, members of the NRC staff and the NRC Commissioners, licensee staff, and members of the public.

As stated above, an employee of the NRC was identified as the Designated Federal Official in compliance with FACA. In addition to his duties under FACA (explained above), the DFO provided overall coordination of the Panel meetings and ensured that Panel members had the information they needed to participate in meetings. The DFO attended all meetings, occasionally represented the NRC to the Panel, and often served as a nonvoting member of the Panel. NRC staff involved in the cleanup at TMI-2 attended all but one of the meetings of the Advisory Panel. These staff members provided regular updates on the cleanup as well as other information requested by the Panel. The NRC Commissioners also met with the Advisory Panel on a regular basis to receive public input about the TMI cleanup. Commissioners did not typically attend the regular meetings of the Panel.

4 A list of the meeting dates is provided in Appendix A.
The GPU Nuclear Corporation (GPUN), commonly referred to as the "licensee," was responsible for the day-to-day cleanup efforts at the facility. Representatives of the licensee attended each Panel meeting and provided updates on the cleanup for Panel members as requested.

Members of the public also participated in Panel activities. Many of the initial Panel mee.ings drew large, standing-room-only crowds, although this level of attendance tapered off through the years. There were less than ten members of the public in attendance at the last few Panel meetings. While members of the public often attended meetings as individuals, others attended as members of, or representatives, of local community activist groups. Members of these local groups, such as Three Mile Island Alert (TMIA), Susquehanna Valley Alliance (SVA), or Concerned Mothers, faithfully attended Panel meetings over the years. TMIA, for example, was originally organized in 1977 to resist the proposed opening of TMI-2. After the accident, TMIA was transformed into the largest activist organization related to TMI, with a seven-member steering committee, 30member planning council, and 12 semiautonomous community group affiliates (Walsh 1981). Membership in TMIA jumped to about 2,000 active members after the accident. Concerned Mothers, another group of citizens local to the accident site in Middletown, Pennsylvania, organized after the incident to raise the health and safety concerns of families in the area. With considerably fewer members than TMIA, Concerned Mothers still sent representatives to most Advisory Panel meetings. SVA, a group of citizens centered in Lancaster Couniy, actively participated in Panel meetings over the years. The SVA was prominently involved in discussions about the disposition of the accident-generated water. SVA members presented options and critiqued alternatives on the disposition of the water, often filing written comments for the transcript record. Members of these and other local 
activist groups frequently made presentations to the Panel and almost always asked pointed and direct questions of other presenters. In addition, they were vocal in their support for expanding the original charter of the Advisory Panel to include discussion of health effects of the accident. Active citizen participants became known by name to all Panel members, NRC staff, and licensee staff who participated in Advisory Panel meetings.

The original Panel charter noted that Panel members woula "consult with and provide advice to the Commission on its major activities required to decontaminate and safely cleanup the TMI-2 facility" (Hoyle 1980b). In 1986, at the request of the Panel, the Commission expanded the Advisory Panel Charter to include the review of health issues associated with the TMI-2 accident. Many issues, including health effects, were discussed by the Panel over the years. Typically, as the cleanup proceeded and new efforts were undertaken, the focus of the Advisory Panel discussions changed to include those new activities. A few topics, however, came up at meetings repeatedly and were discussed at Panel meetings over a long period of time. In addition, the Advisory Panel reported public concerns about these long-term issues to the Commissioners more than once. These issues represent some of the most intractable problems faced by the Advisory Panel (and the cleanup in general) over the years:

- Funding for cleanup and decommissioning

- Disposition of high-level radioactive waste

- Whistleblowing activity at TMI

- Health effects and results of health studies

- Disposition of contaminated "accident" and cleanup water
- Radiation exposure of cleanup workers

- Long-term storage of the facility (prior to ultimate decommissioning).

The date for closing the Panel was left indeterminate in the original Charter because the Panel was to be used as long as there was a perceived need to solicit public views on cleanup issues at TMI-2. By 1993, many NRC staff and Panel members were questioning the continued usefulness of the Panel. For example, the NRC estimated that final approval for the licensee to place the facility in PDMS (long-term storage) would be granted by the end of 1993. Many, but not all, Panel participants viewed this as the natural stopping place for Panel activities. In response to the perceived decline in Panel usefulness as well as an effort to reduce the number of Federal Advisory Panels, the Panel met for the last time on September 23, 1993. A total of 78 meetings of the TMI-2 Advisory Panel were held between 1980 and 1993. 


\section{Lessons Learned from the TMI-2 Advisory Panel}

The information provided in this section is based on the perceptions of the interviewed Panel participants, review of the transcripts, and the literature review. Panel participants' perceptions are not presented as "true" descriptions of the experience of the Advisory Panel. Rather, the descriptions are meant to evoke the Panel experiences of a variety of individuals over a long period of time. Direct quotes from individuals are attributed only by group type (for example, "past Panel member"). If a direct quote cannot protect the confidentiality of a respondent, identifying comments have been removed. In a few cases, a composite quute is created by combining comments from several individuals to reflect a common theme expressed by several respondents. Quotations are taken primarily from the one-on-one interviews conducted for this report. Any quotes or comments taken from the meeting transcripts are designated as such.

The interview and meeting transcripts were read to identify the type of issues and concerns raised by Panel participants. The issues were then analyzed to identify any patterns or themes that were common across the interviews and transcripts. In addition, the literature on citizen advisory panels suggested several points about advisory groups that should be considered in an analysis. These two methods were used to develop the following list of issues for closer analysis:

(1) Panel Objectives

(2) Characteristics that Support Implementation of Advisory Panels

(3) Panel Composition

(4) Meeting Structure

(5) Panel Influence on Cleanup Activities

(6) Role of the Media

(7) Advisory Panel Longevity.
Each of these areas is discussed more fully below, using quotes from the transcripts and interviews to provide details and corroboration of the analysis. A summary of lessons learned about each topic concludes the analysis.

\subsection{Panel Objectives}

The following section reviews both the implicit and explicit original Panel objectives, as well as the ways in which the objectives changed over the years. A summary of the lessons learned about Panel objectives concludes this section.

\subsubsection{Analysis of Panel Objectives}

When asked about the original Panel objectives, most respondents were able to identify the explicit objectives of the NRC in forming the Panel. These obiectives included providing the NRC with input about public concerns and providing the public with information about cleanup activities. NRC staff and early Panel members remembered seeing the objectives in writing and reported that the objectives were brought out on many occasions to determine whether specific topics were appropriate for Panel discussion. Panel members who joined during its later years, licensee staff, and members of the public were much less likely to report having seen the objectives in writing, and their descriptions of the objectives are less formulaic in nature. For example, one NRC staff member reported that the objective of the Panel was to "act as an independent group that evaluates public concerns and relates them to the Commission." This almost verbatim restatement of Panel objectives can be contrasted with the less polished, but still accurate, description provided by a Panel member who joined the Panel relatively late in its history, "... to give the NRC some insight into another perspective besides that of the operating company [licensee]."

Respondents reported that they were familiar with the explicit Panel objectives 
because they were often referred to in attempts to keep Panel participants on topic. Using the objectives as a gatekeeping mechanism was viewed positively by Panel members and less positively by non-Panel participants. For example, one Panel member remembered, "When the Panel went astray from the original objectives, the Panel and the Commissioners reviewed the original objectives ... One of the liaison's (DFO) tasks was to gently remind the Panel what we were supposed to focus on." Another Panel member reported that there were many meetings where the discussion focused on "This is our charge and this isn't our charge." In contrast, a member of the public reported that the objectives were used to "tell people to come back later or save their questions for another, more appropriate, time." This public participant conceded, however, that the objectives were also used to insist that the licensee and NRC provide certain reports to the Panel.

In addition to understanding explicit Panel objectives, respondents also talked about unstated objectives that they believed compelled the NRC to create the Panel. The most often reported implicit objective of the Advisory Panel was to reduce public anxiety about the accident and subsequent cleanup. Other irnplicit objectives included allowing the public to "let off steam," take the "political heat off the Commissioners," "provide assurance that things weren't as bad as they looked," "provide a buffer between citizens and the NRC," and "build credibility for both the NRC and the licensee." All respondents discussed this perceived need to reassure the public and reduce the growing antagonism between the public and the NRC and licensee. In general, respondents believed the implicit objectives were related to the high levels of public anxiety and low levels of NRC/licensee credibility that existed when the Advisory Panel was formed.

Most respondents believed that Advisory Panel objectives did not change throughout the life of the Panel. A few
NRC staff members and Panel members remembered that the charter of the Advisory Panel was expanded to include discussion of possible health effects and funding for the cleanup. Most respondents, however, did not remember or discuss these changes. Review of the transcripts for meetings prior to changes in the scope of Panel objectives revealed many protracted struggles between Panel members and members of the public over appropriate topics for discussion at meetings. Public testimony or questions about health issues were consistently overruled by the Chairman as irrelevant to the Panels' purpose. Anxiety and frustration about the potential health consequences of the accident and the inability to find anyone who would listen to public concerns created a growing antagonism between Panel members and members of the public during the early and miadle years of the Panel. This polarization seriously threatened the perceived legitimacy of the Panel during its middle years until the charter was expanded to include consideration of health concerns. The flexibility that allowed the Panel to address issues of most concern to the public helped the Panel reassert its role as a conduit of information from the public.

Most respondents felt that the Advisory Panel met both the original objectives set by the NRC and many of the implicit objectives perceived by participants. Several respondents reported, however, that because public attendance and participation at Panel meetings declined over the years, the objective of providing NRC with insight about public concerns was not fulfilled. Instead, they argued, the Panel provided the NRC with only the limited insight of Panel members and a small group of active participants.

Licensee respondents, in particular, reported that while they were satisfied that the Panel initially provided a conduit for expression of public concern, they were concerned that the Panel was currently less representative of the general public than it had been in the beginning. Other respondents, however, believed the 
decrease in public attendance may be a result of the perception that the cleanup project is going well and public concern has declined.

Panel members perceived the Panel to have more than met its objectives, especially the implicit objective of increasing public trust in the cleanup process. NRC staff believed the Panel met its objective of providing a conduit for public input to the NRC. Many NRC staff also reported, however, that because the cleanup is so complex, Panel members were unable to provide any meaningful technical guidance. NRC staff were also concerned that the conduit opened by the Advisory Panel provided a forum for reports they considered not credible. They accepted this as a by-product of the openness required to facilitate good-faith discussions butween members of the public and Panel members. Members of the public were more uncertain about whether the Panel had met its original objectives. Most public respondents reported that the Panel was a good source of reliable information about the cleanup and provided a critical review of NRC and licensee activity. They complained, however, that the Panel too often only reacted to NRC or licensee efforts and did not take a proactive stance in promoting certain activities or providing guidance to the Commissic...

\subsubsection{Summary of Lessons Learned about Panel Objectives}

- Original objectives were well known to all Panel participants and were used effectively to keep Panel meetings on track.

- Participants believed that Panel objectives were met, although there was concern that reduced putlic participation also reduced the ability of the Panel to represent the public.

- Participants perceived that implicit Panel objectives included reclucing public anxiety about the accident and cleanup of TMI-2 and believed these objectives were met.

- Panel members were able to reduce growing antagonism and conflict between members of the public and other Panel participants by convincing the NRC to expand the original objectives to include issues of great concern to the public.

\subsection{Characteristics that Support Implementation of Advisory Panels}

The following section analyzes respondents' perceptions of TMI-2 cleanup characteristics that made it amenable to the effective use of an advisory panel. A summary of the lessons learned about these characteristics follows.

\subsubsection{Analysis of Characteristics that Support Implementation of Advisory Panels}

While citizen advisory panels have been used in many situations (see Section 1.2, above), use in circumstances such as the Three Mile Island accident is unique to both the nuclear industry and the public. Instead of comparing the experience of the TMI-2 Panel with those of other advisory panels, we asked respondents to identify characteristics of the TMI-2 situation that they believe supported the implementation and successful use of an advisory panel. Respondents' answers consistently echoed a Panel member's description of the need for a situation with "a traumatic change in the status quo." Characteristics identified by Panel participants in at least two groups are described in Table 3.1 below. 
Table 3.1: Characteristics that support implementation of advisory panels

\begin{tabular}{|l|l|}
\hline CHARACTERISTIC & RESPONDENTS \\
\hline $\begin{array}{l}\text { - High-profile incident, creating concern } \\
\text { across many communities }\end{array}$ & Licensee, NRC, Panel, Public \\
\hline - Traumatic incident & Licensee, NRC, Panel, Public \\
\hline $\begin{array}{l}\text { - People understand what the problem is and } \\
\text { can focus on common goals }\end{array}$ & Licensee, Panel, Public \\
\hline - Controversial issue & Licensee, NRC \\
\hline - Unique event & Licensee, NRC \\
\hline - Loss of credibility and trust & NRC, Panel \\
\hline - Ongoing problem & NRC, Panel \\
\hline - Health fears & NRC, Public \\
\hline
\end{tabular}


Only members of the public suggested that an advisory group can also be an appropriate forum in less traumatic situations, such as discussions about ongoing nuclear plant operations. All other respondents believed that only a situation that is alarming and focused on a high-profile incident, such as the accident at TMI, is an appropriate setting for an advisory panel. A Panel member summed up why Panel members believed a less traumatic situation wouldn't be appropriate: "It's too much work and we couldn't get people to participate for so long." Another Panelist believed that it would be possible to use this model in situations with a specific focus, such as a site selection or facility decommissioning, but agreed "there needs to be a major issue to get the quality of people who served on the TMI-2 Panel."

\subsubsection{Summary of Lessons Learned about Characteristics that Support Implementation of Advisory Panels}

- Successful advisory group implementation requires a highprofile problem with a specific focus.

- Without an appropriate focus, advisory panels are unlikely to attract quality participants or hold their attention for long.

- Maintaining a successful advisory group requires a continuing high public interest in the event.

\subsection{Panel Composition}

This section reviews the balance of competing perspectives that was built into the original Panel membership and continued throughout the life of the Panel even as members changed. The analysis is followed by a summary of the lessons learned about Panel composition.

\subsubsection{Analysis of Panel Composition}

The NRC originally selected Panel members to represent locial and state officials, scientists, and members of the general public. One NRC staff member remembered the reasonin r behind the original selection: "We wanted a balance with members of the loyal opposition [to the licensee and their activities] represented but who were also constructive. We wanted members who were respected by all sides-reasonable, rational people. People who would bring in other perspectives." All respondents believed that the Panel needed to be balanced or representative of the many sides of the issue. This inclusive Pand membership contributed to the perception shared by most participants that all points of view were heard and considered by Panel members. A member of the public summed this point up: "The Panel needs to be eclectic to have credibility."

Respondents recognized and described the way Panel members balanced each other in ideas, personalities, and positions. While the original official balance included three state representatives, three local elected officials, three scientists, and three members of the public, this composition changed over time as Panel members left and new members joined. For example, most of the State of Pennsylvania representatives dropped off the Panel quickly and were replaced by Panelists with technical backgrounds and local knowledge. In the interviews, respondents described balance in Panel composition as deriving from members' diversity of perspective:

- those holding elected office and those not holding elected office

- those with technical and nontechnical backgrounds

- those who held anti-nuclear, pronuclear, and neutral positions 
- those with "local knowledge" and expert knowledge.

The original membership, selected by NRC to be balanced across a political and scientific spectrum, was supported by the additional qualities identified by

respondents. Most respondents identified balancing Panel representation in some way as critical to the effectiveness of the Advisory Panel.

Licensee respondents and NRC staff, in particular, stressed the need for a range of technical capabilities among Panel members. In addition, ispondents felt these technically skilled Panel members should have no vested interest in the nuclear industry. One ex-Panel member reported that the "composition was important -- Panel members respected the technical abilities of other members. The backgrounds varied and it was the job of technical people on the Panel to pursue technical questions." In addition, all respondents, except licersee staff, reported that the vocal presence of wellknown anti-nuclear Panel members was crucial to the credibility of the Panel. One Panel member recalled, "The representatives from the anti-nuclear groups played an important role. They were the ultimate watch dogs." An NRC staff member told us, "[an anti-nuclear Panel member] more than earned his pay. The citizens listened to him. He gave them peace of mind. He was a pain, but a good pain."

The wide range of technical and nontechnical expertise was used by Panel members to educate both themselves and the public. Respondents often described technical Panel members, for example, as translators of the highly technical information presented by the NRC, the licensee, and other experts. While this role is fairly obvious and easy to understand, Panel members and NRC staff also recognized that non-technical Panel members translated public concerns and perceptions so that technically oriented people could view those concerns as valid. One Panel respondent explained,
"The technical and non-technical Panel members would disagree sometimes; nontechnical Panel members would often say to technical members, 'Let's not go uverboard here, let's wait. We don't have all the facts or information [about a technology, procedure, or results] so let's go slow.' It was good for technical Panel members to be reminded of this more conservative view." This technically oriented Panel member had learned to value the perspective of non-technical Panel members.

Licensee respondents, however, reported that technical Panel members were not especially good at translating technical material for non-technical Panel members. They complained that non-technical members could not be convinced by a presentation of the "facts," no matter how clear the presentation or the translation. In addition, licensee respondents perceived that non-technical members were "intimidated" by technical discussions and technical Panel members: "There were two technical members on the [original] Panel. When they spoke, some of the others were intimidated because they didn't understand what was going on. A few of the Panel members, non-technical, never spoke at all during these discussions." Rather than observing panel members educating each other across their respective areas of expertise, this licensee respondent saw intimidation between technical and non-technical members. Panel members themselves did not use the term "intimidation" to describe relationships on the Panel, although several did comment that they were often quiet during their first months because they didn't understand terms or concepts.

Panel members reported that the balanced representation created conflict and adversarial relations among themselves. Rather than seeing tinis as a negative, however, most respondents reported that conflict and disagreement worked to increase the integrity of the Panel. Panel members consistently reported, "All the conflict on the Panel increased credibility. 
The credibility of the Panel increased due to our obvious lack of agreement on many subjects."

Panel members and NRC staff reported that, eventually, trust and respect grew between members of the Panel with divergent perspectives. This respect grew out of months and years serving together in a problem-solving effort and learning that Panel members could keep Panel objectives in mind as they made desisions. A Panel member reported, "I trust the 'anti's' on the Panel because I feel they understand the responsibilities and limits of the Panel objectives." Respondents also reported that respect was created as they came to know each other's varying skills and expertise. An observer of the Panel concluded, "Panel members by and large trusted each other. For example, non-technical Panelists could ask for advice from the technical members."

\subsubsection{Summary of Lessons Learned about Panel Composition}

- A range of expertise increased the capability of Panel members to participate in technical and political discussions.

- Panel members educated both the public and each other across different areas of expertise.

- Diverse perspectives and capabilities increased conflict among Panel participants. This conflict, however, appeared to contribute to the perception that the Panel was a credible or legitimate forum for discussion of the cleanup activities.

- The wide range of Panel members' perspectives also appeared to increase the credibility of the Panel with other participants and observers.

- Although some Panel members were unable to contribute directly during certain technical discussions, they did participate by providing additional perspectives to the issues under consideration.

\subsection{Meeting Structure}

Respondents were asked several questions during the interview about how the Panel meetings were structured. These quicstions focused on establishment of the agenda, how individuals addressed the Panel, and ways in which meeting participation was encouraged or discouraged. Almost without exception, respondents began their discussion of meeting structure with a discussion of the current Chairman. Respondents consistently described the Chairman as doing an excellent job. A composite response from several individuals reveals this respect for the Chairman: "The Chairman was excellent - he kept reasonable order, he was respected by everyone, knew how to run a meeting, and was a gentleman. He deals with disparate views well. I have a lot of respect for him. He is efficient, knows how to run a meeting - a perfect combination of technical knowledge and elected official. I would recommend someone like the current Chairman. Someone who is not necessarily a technical person, but someone who understands government, business, and how the ordinary person thinks. He is fair, responsive, and conducts a good meeting. There was never enough time, but he did what he could. The Chairman needs to be someone the public can trust and who has credibility with the licensee. The Chairman must also be able to run a good meeting -- structured, but friendly."

The current Chairman was almost universally appreciated as a capable individual and there appear to be several functions that contribute to this perception of his chairing abilities. Respondents reported that the current Chairman tended to manage meetings through his personal authority and skills rather than relying on formal rules or power. While this created an informal atmosphere at most meetings, it also created the potential for chaotic 
meetings. Respondents, however, gave accounts of efficient and structured informality. A composite response from Panel members, members of the public, and NRC staff describes a meeting style they all felt comfortable with: "The Panel meetings are informal and congenial. There is a lot of interaction among the Panel members and with the public and utility. The level of meeting formality is very effective and appropriate. The meetings were a blend of formal and serious when necessary and relaxed and fun when necessary. The meetings have a formal framework with many openings for informality. You had to have some formal structure to make it possible for people to speak. But the meetings were not so formal that people felt they couldn't talk." Several of the meeting skills and techniques that contributed to effective meetings are discussed in more detail below.

\subsubsection{Speaking Rules}

Respondents identified the Chairman's ability to facilitate participation as one of the qualities of effective Panel meetings. Even though Panel meetings were often lengthy, there was always time for Panel members and members of the public to ask questions and make comments. A member of the general public had positive memories of the Chairman's willingness to include public input: "The Chairman encouraged participation by setting aside time for the public. He let people exhaust their comments and questions." One Panel member recalled that some members of the public grumbled about lack of time, but believed they were unrealistic in their expectations: "The way the Chairman structured the public comment period was very helpful. The Panel meetings were as open as possible while still maintaining the ability to get things done. People who complained about lack of or shortage of time were immature and didn't understand how meetings worked. Anyone who wanted to could ta!k at meetings."
Panel members were allowed to speak for as long as they wanted or needed to, although speaking time for members of the public was more strictly rationed. However, all individuals addressing the Panel were expected to stay on topic. A licensee staff remembered, "The Chairman was respectful of everyone, he called people by their names and generally made people feel comfortable. Some of the [Panel members] rambled and talked about issues that were outside the scope of the Panel. The Chairman would cut them off or gently put them back on track." The expectation to stay on topic was one speaking rule known to everyone and consistently applied to anyone who addressed the Panel. This evenhanded approach created a perception of fairness, especially among Panel members and members of the public. A member of the public reported that "the Chairman has a nice manner even when admonishing people to stay on the topic."

Another speaking rule used by the Chairman was a requirement that members of the public schedule time on the agenda prior to the meeting if they wanted to make a formal statement. Panel members believed that, "The standard process of making arrangements prior to the meeting date encouraged participation." Individuals who scheduled time were given the first opportunity to use available meeting time. Any additional time was allotted to speakers who did not pre-schedule time. Consistent application of this rule ensured that people who requested time on the agenda were always provided time to speak. There was some flexibility in this rule so that speaking times could be traded, and even aggregated, among members of the public.

Analysis of respondents' accounts of the rules revealed no perceptions that favorites were played or that the speaking rules were misused. Respondents did have complaints, however, about the speaking rules. For exanuple, licensee staff did not like members of the public aggregating time so that one speaker 
could speak for more than the allowed three to five minutes. Members of the public felt that, in general, more time should have been allotted during meetings for public comment. One member of the public objected, "You need to request time ahead if you wanied more than the normal two minutes. Most of these requests are granted although it felt like you were pleading to say a few words. It was controlling and demeaning." Another member of the public remembered participation in Panel meetings more positively, "I got whatever time I needed or wanted. I felt the Panel respected my presentations and perspectives."

\subsubsection{Setting the Agenda}

While many topics were generally covered during each meeting, the structure of the meeting evolved over the years to include a routine or standard agenda. A review of the transcripts suggested that a typical agenda allowed for update reports from the licensee and NRC, reports from other agencies as necessary (e.g., Environmental Protection Agency or Department of Energy), and a public comment period. In addition, topics of special concern were scheduled as needed. These special topics were usually generated by current cleanup activities or public concerns. Agenda items were identified at the end of each meeting for the next meeting, during the interim between meetings through discussion with the Chairman, or at the beginning of each meeting.

Agenda setting was relatively informal: a wide range of mechanisms was used to identify appropriate topics; meeting attendees received the agenda at the beginning of the meeting; and agenda items were often added or subtracted on an informal basis. This type of informality can suggest to participants that getting items of concern on the agenda is an open and inclusive process. Most respondents reported that informal agenda setting was comfortable and usually effective in ensuring that the Panel addressed important issues. A composite response from members of the public, Panel members, and NRC staff participants describes how the informal process worked: "At the end of each meeting, the Panel would decide on the agenda. Between meetings they sometimes add things. Or new things came out and that would be added. The public also expresses interests about what they want discussed. The public has a lot of guidance on meeting topics and agenda."

Despite the informal nature of agenda setting, respondents reported that the agenda itself was adhered to rather rigorously during most meetings. The agenda appeared to be used, as necessary, to keep people on topic and on schedule. A composite response describes how the agenda was used to control meetings: "No one really knows the exact agenda until the night of the meeting. The point was not to give the utility or the public an edge - no one could have an advantage by having the agenda early. The agenda was constrained by time - we really only wanted to spend about two or two and a half hours at each meeting. The Chairman made attempts to keep people on time." While not explicitly complaining that the Chairman used the agenda as a control mechanism, some respondents reported that the use of the agenda in this manner makes them uncomfortable. One Panel member protested, "I didn't always receive an agenda in the mail so I couldn't prepare for the meeting beforehand. I complained to the Chairman but it didn't change anything." Using the agenda as an impersonal referee to keep partic:pants on track during meetings is another example of how the Chairman used his skills, rather than the power of his position, to enforce control of meetings without alienating too many participants.

\subsubsection{Meeting with the Commissioners}

As part of the original Panel Charter, Advisory Panel members were required to condense or synthesize the information 
they received from the public and report to the NRC Commissioners in regular meetings. Transcripts of the meetings with Commissioners revealed that this synthesized information was most often reported in casual discussions between Commissioners and Panel members about recent agenda topics. When asked during the interviews about the meetings, most Panel members remembered that the Panel often reached a consensus about which items would be discussed prior to meeting with the Commissioners. The Panel also developed consensus positions about specific issues before meeting with the Commissioners. Panel members did not clearly remember what type of process they used to build consensus. For example, one Panel member reported:

"There is no real effort to develop a Panel position, instead it is a more informal consensus seeking. There would be the formal comment by the Chairman [to the Commissioners], but individual Panel inembers could add their comments. I don't remember any internal Panel fights over what to say to the Commissioners." Another Panel member remembered more of a struggle over consensus development: "There is always some controversy when it comes time to determine rciommendations for the Commissioners because of the different perspectives represented on the Panel. But it was all done in good spirit." One Panel member summed it up with the observation, "We tried for a consensus on recommendations to the Commissioners and Panel positions. But, we had no control over the diverse Panel and really couldn't hide anything like differences in opinion even if we had wanted to."

Panel members reported they felt it necessary, on occasion, to develop a more formal Panel position on specific topics. Topics identified as needing a Panel position usually had high visibility with the public such as plans for the disposition of the accident water. Official positions were also developed when Panel members felt they were not receiving an appropriate response from the licensee or agency. For example, when repeated requests for a response to charges that the licensee was harassing whistleblowers went unanswered, the Panel developed a more formal position and request. An official Panel position (usually with both inajority and minority views attached), was assumed by Panel participants to represent the views of the public. The legitimacy of the position taken by the Panel appeared to inhere in the balanced composition of the Panel; each Panel member was assumed to represent a certain viewpoint held by some portion of the gen ral public. By taking a vote, developing a consensus, or negotiating a position, the Panel was standing in for a larger public vote, consensus, or negotiation.

\subsubsection{Changes in the Meeting Structure}

Respondents reported, with few exceptions, that the informal structure of the meetings stayed essentially the same over the years. The most notable structural change was scheduling of the public comment period. Originally, public comment was delayed until all other agenda items were compiete. By that time, it was usually late in the evening, discussion had touched on many issues, and many members of the public had already left for home. Review of the early transcripts suggested that allowing individuals to comment only at the end of the meeting created frustration and an adversarial relationship between Panel members and members of the public. It is likely that Panel members were not only hearing individuals express frustration with the way the cleanup activities were progressing. They were also hearing public anger about the lack of time to question presenters and the necessity to condense all concerns, comments, and questions into the allowed period at the end of the meeting. For example, one member of the public remembered, "There was not enough time [given] to the public point of view. Really often all that people wanted was to know that someone had heard them give their point of view." 
Another consideration was that reporters from local television and newspapers often left the meetings early. Scheduling public comment at the end of the Panel meetings denied the public access to the media. Disallowing public comment until late in the meeting and evening also led to an attrition factor. Some members of the public left the meetings before they were over, leaving individuals who were highly committed (or with fewer demands on their time) as the sole representatives of the public. Organizing the meetings in this way made it likely that moderate individuals did not participate in discussions during initial Panel meetings. After Morris became Chairman, a change in meeting structure was made to include one public comment period after the major presentation (usually about half way through the meeting) and another at the conclusion of the scheduled presentations. Analysis of the transcripts suggested that after the meeting structure was changed to include this earlier public comment period, more individuals participated in the public comment period and public-initiated questions related more directly to the agenda items. During interviews, respondents recalled the earlier structure with some intensity and in great detail, but were less likely to provide any comment at all about the current arrangements. This suggests that the current meeting structure is taken for granted and accepted as an appropriate method for including individuals in the discussion.

\subsubsection{Suggested Improvements for Meeting Structure}

When asked to suggest improvements in the way meetings were conducted or methods to improve meeting participation, respondents were generally hard pressed to identify specific changes they would like to see made. Most commonly, respondents requested increased resources for the Panel, including funds to bring in outside experts, pay Panel expenses, and administer the Advisory Panel. One NRC staff member told us, "Expenses for Panel members was an issue from day one. We did a poor job on servicing their reimbursements and I don't understand why. It was not legitimate to pay Panel members, but I can't exactly remember why the original decision was made. It was not a budgetary constraint. Maybe Commissioners didn't want to set a precedent for paying citizen Panel members." Panel members, almost to a person, were concerned about reimbursement for Panel activities. 5 The transcripts reveal that this topic was discussed at almost every meeting during the past few years, although the manner of the discussions was a genial joking between Panel members and the NRC DFO. A composite of Panel responses suggests the nature of their concern: "The NRC should have been more responsive to Panel expenses. I felt that we were nickeled and dimed by the NRC. I bet the NRC is paying more for this research than for all twelve years of Panel expenses. Panel members may be more objective if they aren't paid, but not paying Panel members sends a message of low priority."

Other suggestions for improving Panel meetings included providing more technical support to the Panel, having the Commissioners attend the Panel meetings on a regular basis, and rethinking how Panel members should be selected and/or replaced. A composite response from Panel members, NRC staff, licensee staff, and members of the public explains the nature of their concerns about Panel membership: "There was little discussion among the Panel members about replacements for members who left. This created some question in certain citizens' minds about whether the replacements represented the public. Panel members

\footnotetext{
5 Although the decision was made not to compensate Panel members for their participation, the NRC agreed to pay their expenses. Federal travel regulations, under which members were reimbursed for expenses, prohibited payment of per diem for most Panel members. Panel meetings were of too short a duration to qualify for the per diem payment.
} 
were not asked to provide any input on the replacements. After the elected officials left office, they most often stayed on the Panel. This was not appropriate since they no longer represented the public in the same way. We should have at least talked about it." Only one respondent (licensee staff) suggested term limits for Panel members as an improvement. Others felt that the issues and topics were so complex and complicated that a relatively long period of time was required before individuals were effective Panel members. Members of the public thought that more agenda time should be devoted to citizen input. They believed this would have allowed them to make more thoughtful presentations about complicated issues.

\subsubsection{Summary of Lessons Learned about Meeting Structure}

- Consistently applied speaking rules created a perception of fairness among Panel participants.

- An informal atmosphere provided the appropriate flexibility for wide participation.

- Impersonal methods of controlling meetings maintained respect for individual perspectives.

- Frequent, but controlled, periods for public participation increased the quality and quantity of input and reduced ongoing conflict over meeting procedures.

- A mid-meeting public comment period increased the range of public response and reduced increasing tensions between citizens and Panel members.

- Recommendations and reports to the NRC Commissioners were most often developed through informal consensus building among Panel members.
- Respondents believed that improvements could be made to the Advisory Panel by increasing resources for the Panel, increasing the technical support by the NRC DFO, and reassessing how Panel members are selected.

- Term limits for Panel members did not appear feasible to most participants due to the complexity of cleanup issues.

\subsection{Panel Influence on Cleanup Efforts}

The following analysis focuses on respondents' perceptions of the role played by the Panel in the cleanup efforts at TMI-2. The analysis is followed by a summary of lessons learned about Panel influence.

\subsubsection{Analysis of Panel Influence on Cleanup Efforts}

Respondents were convinced that the Advisory Panel did have influence on the cleanup activities at TMI-2 although they had difficulty untangling the direct influence of the Panel from the other pressures on the licensee during the cleanup period. Even though most respondents were unable to identify any examples of direct technical influence on the cleanup, they did believe that the Advisory Panel played other significant roles in the cleanup process.

All respondents identified one important role of the Panel as increasing public scrutiny of both licensee and agency cleanup activities. Members of the public atd the Panel were observing and questioning the licensee and the NRC in public; answers to those questions were also provided in public. Respondents recalled that many questions posed by the Panel were asked in no other public forum. One NRC staff member described participation in the Panel as the only consistent "source of contradictory 
information for GPU." 6 Both the licensee and challengers to the licensee were expected to present and defend their positions in public, which all respondents felt was beneficial to the cleanup. One member of the public described this role of the Panel as "extending the reach" of the general public, allowing them to hear and participate in discussions about the cleanup to which they normally had no access. NRC staff members believed that the scrutiny of the Advisory Panel forced the licensee to think through their plans very carefully before presenting them to either the agency or the Panel.

Respondents also reported that the existence of the Advisory Panel influenced the way information about the cleanup was delivered and presented. Technical information was prepared by both the NRC and the licensee for wide dissemination and understanding by members of the lay public. In addition to providing a conduit between the NRC and the public, Panel members believed they also facilitated communication between the licensee and the public. Issues were highlighted by the Panel so that licensee staff could know what was important to the public, were sensitized to public concerns, and would hear the public perspective. One NRC staff member corroborated this communication role by observing that "the advisory Panel helped in packaging the cleanup issues for the public. If a general public consensus developed about a specific issue, the Panel helped focus or concentrate that consensus." A licensee staff member believes that "participation in the Panel provides [the licensee] with a constant reminder and better perception of what issues the public was concerned about."

6 Most respondents referred to the licensee as "GPU." While GPU is technically the parent company of the licensee GPUN, we believe that the respondents are referring to the licensee (GPUN) in their responses because they consistently switch back and forth between the terms GPU and licensee. In deference to respondents' statements, we retain the references to GPU.
Respondents' analyses of the Panel's technical contribution to the cleanup were quite divergent. Licensee staff, for example, were fairly certain that the Advisory Panel contributed no technical guidance during the cleanup. They admitted, however, that some Panel members, particularly those with technical backgrounds, raised interesting issues which were followed up by the licensee. One licensee respondent conceded that "the Advisory Panel raised issues that [GPU] had to consider. If a technical person, in particular, raised an issue, we heard it. It got us to listen." NRC staff were more confident that Panel members contributed substantially to technical issues. NRC staff believed that, at the very least, Panel members insisted that a wider range of technical alternatives be considered or developed. One NRC staff member reported, "[A Panel member] first brought up the idea of PDMS (postdefueling monitored storage) in a Panel meeting. I can't honestly say the licensee hadn't given PDMS some previous thought, but the idea was first discussed at Panel meetings."

In general, Panel members believed they provided some level of technical guidance for the cleanup, although it was difficult for Panelists to identify specific instances where their questions or ideas changed the technical course of the cleanup. One technical Panel member conceded, "I do [believe we had some technical influence on the cleanup], but I don't know how much. Our questions made them go back and think ... Some questions influenced GPU and NRC to look into things more thoroughly and carefully.... Overall, GPU did an excellent technical job."

\subsubsection{Summary of Lessons Learned about Panel Influence on the Cleanup}

- The most crucial Panel influence on cleanup activities was the increased openness to public scrutiny of both NRC and licensee decisions and activities. 
- The Panel facilitated communication with the public for both the NRC and licensee. This communication helped sensitize the agency and the licensee to public concerns.

- The Panel's degree of technical influence on cleanup activities was modest and, in any case, difficult to untangle from other pressures put on the licensee. Most respondents agree, however, that Panel and public questions expanded the range of alternatives considered by the NRC and the licensee.

\subsection{Role of the Media}

The following analysis focuses on the role played by the media as it covered the Panel's activities over the years. While only one interview was conducted with a long-term media participant, all interviewees discussed the role of the media over the years. The analysis is followed by a summary of the lessons learned about the role of the media.

\subsubsection{Analysis of the Role of the Media}

The Advisory Panel meetings received extensive media coverage during the early years, although this lessened considerably over the years. One participant complained that recently, "Stories about Panel meetings and cleanup activities end up on the fourth page of the sports section." Another interpretation of fourth-page stories is a decreased level of controversy and meetings that effectively and efficiently covered the issues.

Both local newspapers and television provided coverage at most meetings. Reporters covering this beat often retained the assignment for years. A media respondent reported "that the topic is so complicated it took years to figure out exactly what was going on." This complexity may be reflected in Panelists' perceptions that "at the beginning, the media blew things out of proportion, elaborating on certain things. They were not very accurate because they usually didn't get the whole story." By later years, however, Panel members reported general satisfaction with the technical content of stories, because they were "very straightforward and mostly correct." Panel participants reported both advantages and disadvantages of media coverage of Panel meetings. One disadvantage mentioned by several respondents was that some participants "play to the camera," often exaggerating their positions to make interesting stories that the media will pick up. One Panel member thought that the effect of this kind of media coverage "only exacerbates the differences between the NRC and GPU." Some respondents also believed that media presence encouraged irresponsible individuals to make claims that are "counterproductive to understanding the real issues."

In general, however, most Panel participants believed that the role of the media was generally a positive one for the Advisory Panel. NRC staff, Panel members, and members of the public all reported that the most important role of the media was to disseminate information about cleanup activities to an audience wider than the one the Panel could reach at each meeting. One NRC staff member believed that a positive side effect of this dissemination was having to prepare and present reports that were polished and could stand up to the glare of television lights. In addition to widely disseminating information from the licensee, NRC, and other agencies and experts, the media also provided a wider forum for asking and answering questions in public. This increased the ability of Panel participants to scrutinize cleanup activities, which most respondents felt was a vital role of the Panel. In addition, one Panel member believed that the media attention "gives the Panel a sense of encouragement because they know residents of the area are getting information about the Panel activities through the media." Otherwise, he said, most Panel activities would have been lost 
on area residents, and Panel members would feel as if their efforts were in vain.

\subsubsection{Summary of Lessons Learned About the Role of the Media}

- Local media covered Panel meetings throughout the years. In the early years, front-page coverage was common. During later years, stories moved to back pages with other, less controversial, news.

- Media coverage disseminated cleanup information to a wider audience than was reached through the Panel meetings.

- Media coverage encouraged high quality presentations.

- Some participants believe that media coverage provided increased opportunities for grandstanding and irresponsible claim making.

- Media coverage may have reinforced the significance and value of Panel activities to Panel members and encouraged their continued participation.

\subsection{Advisory Panel Longevity}

The following analysis focuses on how the Panel was sustained as an effective entity over the thirteen years of its existence. The analysis is followed by a summary of lessons learned about effective advisory panel longevity.

\subsubsection{Analysis of Advisory Panel Longevity}

The Panel met for the first time on November 12,1980, almost one year and nine months after the accident, and continued to meet thereafter for 13 years. Prior to the formation of the Panel, the NRC held public meetings in the general area of Three Mile Island. One NRC staff members recalls the "infamous Liberty Township Fire Hall meeting which got out of hand. [The NRC] received a $\$ 1000$ damage bill." A series of ad hoc meetings were also held with concerned citizens, representatives of state and local government, and licensee staff in order to find a more organized way for NRC to receive input about the cleanup efforts. Several respondents remembered that the local activist group, Three Mile Island Alert (TMLA), was insistent that citizens be involved in the cleanup in some way.

No respondent recalled the formulation of the Panel as particularly slow. What they did report was initial concern about the purpose of the Panel and some apprehension about how best to involve citizens in Panel activities. The transcript of the first meeting is revealing. Before members can be introduced, conflict between the first Chairman of the Panel, John Minnich, and a member of the public arose over the role of the public (NRC 1980: 2-3):

Mr. Minnich (Chairman): Folks, I welcome all of you and your interest in this meeting. I must say to you this evening that I do not believe that we will have an opportunity for public discussion tonight from the audience, not because we don't want to hear your views, but simply because if the rest of the Panel is like myself, we are groping for some answers tonight, and I think that is the prime reason for this meeting tonight is to give us some direction and purpose to that direction.

Mr. Horgan (member of the public): Excuse me, sir. If you're going to give direction to the Panel and Mr. Denton is going to advise you on what steps you are going to take, don't you think that the people of the area should also be giving you dir ection?

Mr. Minnich: At an appropriate time. The next time, please, I will hear you if you will raise your hand, but don't interrupt me. Let's not get started on the wrong foot tonight, please.

Mr. Horgan: Excuse me, sir, but before you can decide what you are going to study don't you think that you should 
hear what we want you to study? This Panel --

Mr. Minnich: No, I don't. You are out of order. And if this is the kind of thing you are going to start right off the bat, then there is no purpose in my being here or anybody else being here.

Now, if you will sit down and listen to the proceedings, maybe you will learn something like I hope to learn something, and when we want your input -- and you will have a chance for input -we will ask for it. I do not anticipate that your opportunity will arise this evening.

The tone set by this exchange in the earliest moments of the Citizens' Advisory Panel raised serious concerns for the members of the public we talked with. They reported that they stuck with the Panel over the next few hours, as well as the next 13 years, because there was no other option. A Panel member sums ups this perception, "... the Panel was the only game in town. The Panel was the only open meeting about the cleanup activities at TMI-2."

Obviously, the Advisory Panel was not a quick fix to any of the problems facing the NRC regarding the cleanup of TMI-2. It took many years for some participants to just gain enough technical knowledge to be effective Panel participants. It also took many years for rapport to develop between the Panel participants. One NRC staff member believed, "The two most significant factors in maintaining the dialogue [between the NRC and the public] were time and the existence of the Panel. As the licensee succeeded in its cleanup activities, the public became more comfortable with what they were saying at meetings. . . . As the public got to know more details, they got more comfortable. For example, the videos that the licensee showed of their activities were very helpful for both the Panel and the public." A Panel member reported that "trust [of licensee and NRC] was built up by their carrying through on actions, explaining problems, telling the truth."
Another Panel member thought "it took maybe ten years for the public trust of NRC and GPU to emerge." A fellow Panel member expressed concern that the working relationships between Panel participants, which took years to build, were not being institutionalized in the licensee organization. The respondent believes that "reverting back to the old antagonistic way [between the Panel and the licensee] is still a possibility as new GPU people, without any history with the Panel, start to work with the Panel." Several respondents reported that in a recent Panel meeting, a GPUN official displayed a defensive communication style, reminiscent of the earliest Panel meetings. They all expressed surprise that licensee staff familiar with Advisory Panel meetings had not prepared this official for the relatively nonconfrontational style of Panel meetings. One Panel member remembered that this institutional forgetfulness was a pattern with the licensee over the years: "The utility tends to shoot itself in the footwhenever they have a good thing going, they shoot themselves in the foot."

It is also likely that the apparent trust between the NRC and other participants has not yet been institutionalized beyond personal contact with NRC staff at TMI and the NRC Panel DFO. Members of the public were particularly likely to report that individual interpersonal contact with local NRC staff was satisfactory, but this did not translate into an increased level of trust for the NRC (or the licensee) in general.

The longevity of the Panel did allow divergent views and interpersonal problems to be smoothed over by participants' shared experience and knowledge. Panel participants got to know each other over the course of thirteen years. One Panel member reported that he began his Panel tenure with a strongly held perspective on one side of the anti-/pro-nuclear spectrum. Over the years, however, he found himself agreeing more and more with Panelists who he believed originally 
represented the other side. A fellow Panelist echoed this perspective: "I trust my opponents on the Panel more than the ones in the audience because they heard the same presentations I did, understood the responsibilities of the Panel, and knew the limits of what we were trying to do." If the Panel hadn't been allowed to mature in this way, antagonism and distrust between Panel members would not have been transformed into the almost universal perception of Panel success.

Panel members were equally divided when asked whether the Panel should continue to operate. Every Panel member, past and present, expressed surprise that the Panel had survived for 13 years. Panel members who thought the Panel should come to an end believed that the most important issues had been addressed and resolved by the Panel and the cleanup efforts. Past Panel members reported their primary reason for resigning was the completion of what they perceived to be the major cleanup activities. Panel members who favored continuing the Panel expressed concern that without the Panel, the public would have no forum in which to express their concerns about activities at TMI. Several milestones still remained, including plans for the post-defueling monitored storage (PDMS) and funding for decommissioning, and these Panelists expressed willingness to continue their service to the Panel until these discussions are complete. However, even those Panel members who thought the Panel should continue, believed the Panel was in the "home stretch."

\subsubsection{Summary of Lessons Learned about Advisory Panel Longevity}

- Many participants continued with the Panel in spite of initial concerns about its efficacy because it was the only forum available for participating in discussions about the cleanup.

- The longevity of the Advisory Panel served to smooth over divergent views of Panel participants, allowed enough time for individuals to learn about the complicated technical issues involved in the cleanup, and created an almost universal perception that the Panel was an effective communication forum.

- Although interpersonal trust between Panel participants is generally quite high, this trust has not typically been translated into increased trust for the institutions or organizations that other participants represent.

- All past and present Panel members expressed surprise that the Panel survived for 13 years. Even those Panel members who believed the Panel should continue thought the Panel had only a few issues left to address. 


\section{Conclusions}

\subsection{Effectiveness of TMI-2 Advisory Panel}

Although the purpose of this report is not to assess the effectiveness of the TMI-2 Advisory Panel, the respondents' interviews provide some evidence about perceptions of Panel effectiveness. In general, the Advisory Panel is deemed a success by all interviewed participants, although all participants also have some criticism of Panel activities or objectives.

A licensee respondent succinctly expressed a general perception among participants that "the NRC got more out of this Panel than it was entitled to. What started out as a palliative device turned into an effective communication channel." Responding to mounting pressure to "do something about the increasing numbers of near-hysterical people" contacting the NRC about TMI-2, the Panel grew into a two-way communication forum for participants. Most respondents believe that the Panel introduced and legitimized the consideration of public concerns in the development of cleanup plans.

Licensee staff reported that participating in the Panel helped them formulate their message effectively so they could get their message and "the facts out to the real public and the press." Implied in the previous statement is a strong criticism by licensee respondents that the Panel did not truly represent the public. From their perspective, the Panel was strongly slanted to the "anti-nuclear" side of the continuum. According to a licensee respondent, the Panel "never effectively presented both sides of the story. The "pro' side never got a real hearing." Interestingly enough, members of the public had the same criticism of the Panel, although they perceived that the Panel provided more attention to, and opportunity for, the proponents of nuclear energy. As additional evidence of this bias, public respondents pointed out that lay people constituted only $25 \%$ of the Panel membership.
In general, however, respondents perceived the Panel as "a TMI-2 experiment that worked." A member of the public believed that the "commitment from Panel members was extraordinary. This component of the Panel experience may not be reproducible." In reply, several Panel members shared in the sentiment that participating on the Panel "was not fun, I didn't like doing it. But I keep doing it and I'll keep doing it because it is an effective public forum. It stimulated a public dialogue about the cleanup of TMI-2 that never would have taken place otherwise." A few Panel members admitted, somewhat sheepishly, that participation on the Panel, while exhausting, was "great fun. It is a tremendous educational experience - I know so much about how things work at TMI-2. One of the reasons I stayed was because I enjoyed the unique insight the Advisory Panel gets into the cleanup."

\subsection{Implications for NRC}

The TMI-2 Advisory Panel is perceived by participants and observers as a success in meeting its objective of opening up a communication channel between the public and the NRC. This reflects the findings in the literature that advisory panel objectives can serve both citizens and public decision makers. The development and focus on a set of wellknown and concrete objectives appears to have helped the Advisory Panel be productive and effective over the years. However, this focus on a limited set of objectives may also have limited the scope of the Advisory Panel's effect.

The literature about advisory panels suggests that participation on or with an advisory panel increases public satisfaction with social institutions more generally. It does not appear at this time that Panel participants share this expanded satisfaction. There does not appear to be any institutionalization of relationships between the public, the Panel members, $\mathrm{NRC}$, and the licensee beyond the strong, interpersonal relationships developed over 
the years of Panel participation. While Panel-related interaction with the public about TMI-2 cleanup activities uppears to be somewhat normalized, there is no guarantee that these relationships will endure if another problem arises at Three Mile Island in the future. This may be partly a result of the decision by the NRC to keep the Panel focused strictly on TMI2 cleanup activities or the practice of limiting the number of staff involved in Panel activities or presentations. Instead of building a wider relationship with the NRC and all of its activities and employees, Panel participants are limited to interactions with a limited number of NRC employees about a constrained set of topics.

The original structure of the Panel, which emphasized a broad representation of scientists, officials, and citizens, effectively initiated a legitimacy or credibility for the Panel with most of its potential audience. Panel credibility was also enhanced by several other phenomena. There is widespread recognition that while the diversity of viewpoints on the Panel often created conflict among members, it also provided the credibility required for continued participation by active members of the public as well as acceptance of Panel activities by the licensee. These two groups of participants perceive that they are underdogs with the Panel, which suggests that Panel members treat representatives of both groups evenhandedly. Panel credibility was also increased by the quality of individuals who served diligently for years. Finally, individual Panel members and the Panel as a whole are perceived by participants as distinct from, and unbeholden to, the sponsoring agency.

Both members of public interest groups and the licensee question whether the Advisory Panel represents the public at large. Most members of the public in Three Mile Island area never attended Panel meetings or other activities related to the cleanup. It is likely that these individuals were at least satisfied, if not pleased, with the cleanup effort. Technically, the Advisory Panel can best be characterized as representing that subsample of the population most actively interested in the cleanup of TMI-2. Low levels of participation by this subsample of the public does not necessarily suggest that they feel unrepresented by the Panel. It is equally likely that they feel very represented by the Panel and by individuals who consistently attend meetings. One official of TMIA reports that membership went from less than 100 members before the accident at TMI-2 to about 2,000 current members. These members know that TMIA follows cleanup activities carefully, participating not only in Panel activities but in other efforts as well, including litigation and monitoring programs. Other, non-TMIA members of the actively interested public are likely to feel fairly well represented by the broad range of perspectives on the Panel at any given time. It is probable that if the Advisory Panel did not represent the views of the public that is interested in the cleanup of TMI-2, the NRC would have experienced more pressure from these individuals and groups to provide meaningful ways to participate in the cleanup discussions.

Supporting the Advisory Panel for 13 years was a modest commitment of resources by the NRC. It is not possible to use the information from this study to calculate either the costs or the benefits of the Advisory Panel. However, given the psychological trauma of the accident, the sense of betrayal by local, state, and federal officials, and people's fear for their own and their children's physical health, it is probable that the pressure on the NRC to support some method for individuals and groups to participate in the cleanup discussions would have continued to mount in the months after the accident. Instead, the implementation and continued support for an Advisory Panel considered legitimate by most potential participants defused that pressure so that NRC, licensee, and public attention could be turned to the technical aspects of the cleanup. 


\section{References}

Ashford, N." "Advisory Committees in OSHA and EPA: Their Use in Regulatory Decision Making," Science, Technology, and Human Values, 9: 92-82.

Beatty, K. and J. Pierce, "Representation and Public Involvement in Water Resource Politics: A Comparison of Six Participant Types," Water Resources, 12: 1005.

Bisogni, C., A. Lemley, and J. FessendenRaden, "Decision Making and Risk Management by Individuals: NitrateNitrogen in the Clifton Springs, New York, Public Water Supply." Technical Report for the Office of Water Research and Technology, Washington, D.C., 1983.

Carpenter, S. and W. Kennedy, Managing Public Disputes, Jossey-Bass, San Francisco, California, 1988.

Christopoulo, G., "An Evaluation of Policy Related Research on Citizen Participation in Municipal Service Systems: Legal System." Monograph No. 7, Technical Assistance Research Programs Institute, Washington, D.C., 1974.

Desario, J., and S. Langton, Citizen Participation in Public Decision Making, Greenwood, New York, 1987.

Doerksen, H. and J. Pierce. "Citizen Participation in Water Policy Formation," paper presented at the Annual Meeting of Western Political Science Association, Seattle, Washington, March 20-21, 1975.

Dunn, J., Jr., "Public Participation in Landfill Siting Process Can Help Smooth the Way," Solid Wastes Management Refuse Removal Journal, 22: 81-82.

Hannah, S. and H. Lewis. "Internal Citizen Control of Locally Initiated Citizen Advisory Committees: A Case Study," Journal of Voluntary Action Research, 11: 39-52.
Hoyle, J., "Three Mile Island Unit 2 Advisory Panel; Establishment," Federal Register 45: 71692, 1980a.

Charter for Advisory Panel for the Decontamination of Three Mile Island, Unit 2. U.S. Nuclear Regulatory

Commission, Washington, D.C., $1980 \mathrm{~b}$.

Hughey, J. and E. Sundstrom, "Perceptions of Three Mile Island and Acceptance of a Nuclear Power Plant in a Distant Community," Journal of Applied Social Psychology 18: 880-890.

Konnheim, C.S., "Public Participation in the Siting of Resource Recovery

Facilities," paper presented at the Annual APCA Meeting, Dallas, Texas, June 1924, 1988.

Kostmayer, P., M. Udall, and M. Lujan, Jr., Letter from House Committee on Interior and Insular Affairs to J. F. Ahearne, Chairman, U.S. Nuclear Regulatory Commission May 13, 1980.

Krimsky, S., "Beyond Technocracy: New Routes for Citizen Involvement in Social Risk Assessment," Citizen Participation in Science Policy, (J.C. Peterson, ed.) The University of Massachusetts Press, Amherst, Massachusetts.

Landre, B. and B. Knuth, "Success of

Citizen Advisory Committees in Consensus-Based Water Resources Planning in the Great Lakes Basin," Society and Natural Resources , 6: 229. 257.

Martin, D., Three Mile Island: Prologue or Epilogue? Ballinger Publishing Company, Cambridge, Masssachusetts, 1980.

Michels, M., "Involving Citizen Advisory Committees Helps Siting," World Wastes, 30: 36-37.

Morgan, D. and R. England, "Evaluating a Community Block Grant Program: A Citizens Group Perspective," The Policy Studies Journal pp. 295-304. 
Nelkin, D., "Science and Technology: Policy and the Democratic Process," (J. Peterson, ed.) Citizen Participation in Science Policy, University of Massachusetts Press, Amherst, Massachusetts. 1984.

U.S. Nuclear Regulatory Commission (NRC), transcript of the Advisory Panel on the Decontamination of Three Mile Island Unit 2, November 12, 1980.

Pearce, J. and J. Rosener, "Advisory Board Performance: Managing Ambiguity and Limited Commitment in Public Television," Journal of Voluntary Action Research, 4: 36-47.

Peterson, J., Citizen Participation in Science Policy, University of Massachusetts Press, Amherst, Massachusetts. 1984.

Priscoli, J., "The Citizen Advisory Group as an Integrative Tool in Regional Water Resources Planning," (Daneke, Garcia, and Priscoli, eds.) Public Participation and Social Impact Assessment, Westview Press, Boulder, Colorado. 1984.

Redburn, S., T. Buss, S. Foster, and W. Binning, "How Representative are Mandated Citizen Participation Processes?" Urban Affairs Quarterly, 15: 345-352.

Reinking, R. and P. Berkholz, "A New Role for Citizens in State Park Planning: Saugatuck Dunes State Park," Michigan Academician , 15: 99-109.

Robin, H. and S. Hannah, "Relationships Among Committee Members, City Administrators, and City Council Members with Respect to the Tasks and Impact of Locally Initiated Citizen Advisory Committces," paper presented at the Annual Meeting of the Society for the Study of Social Problems, 1984.

Shanley, R.A., "Attitudes and Interactions of Citizens' Advisory Groups and
Governmental Officials in the Water Resources Planning Process," technical report for the Office of Water Research and Technology, Washington, D.C., 1976.

Sills, D., C.P. Wolf, and V. Shelanshi, Accident at Three Mile Island: The Human Dimensions, Westview Press, Boulder, Colorado. 1982.

Sorenson, J., J. Soderstrom, E. Copenhaver, S. Carnes, and R. Bolin, Impacts of Hazardous Technology: The Psycho-Social Effects of Restarting TMI1, State University of New York Press, Albany, New York. 1987

Wald, N., "The Nuclear Regulatory Commission's TMI Decontamination Advisory Panel and Public Stress Mitigation," (Ricks, Berger, and O'Hara, Jr., eds.) The Medical Basis for Radiation-Accident Preparedness III: The Psychological Perspective, Elsevier Press, New York. 1982.

Walsh, E., "Resource Mobilization and Citizen Protest in Communities Around Three Mile Island," Social Problems, 29(1): 1-21. 


\section{Appendix A}

Panel meeting dates and transcript microfiche addresses ${ }^{7}$

\begin{tabular}{|c|c|}
\hline MEETING DATE & MICROFICHELOCATOR NUMBER \\
\hline $12 \operatorname{Nov} 80$ & $07071-017 \quad 07071-129$ \\
\hline $18 \operatorname{Dec} 80$ & $07473-180 \quad 07473-274$ \\
\hline $30 \mathrm{Dec} 80$ & \begin{tabular}{|lll}
$07473-275$ & $07474-028$
\end{tabular} \\
\hline $4 \mathrm{Feb} 81$ & $07743-130 \quad 07743-226$ \\
\hline TाFeb 81 & $90215-142 \quad 90215-198$ \\
\hline $9 \mathrm{Jul} 81$ & \begin{tabular}{|c|c|}
$09208-001$ & $09208-082$ \\
\end{tabular} \\
\hline 1 Sep 81 & $09891-072 \quad 09891-204$ \\
\hline $210 \mathrm{ct} 81$ & \begin{tabular}{|ll}
$10338-026$ & $10338-136$
\end{tabular} \\
\hline 16 Nov 81 & $\begin{array}{|ll|}12918-253 & 12918-360\end{array}$ \\
\hline $10 \mathrm{Dec} 81$ & $\mid 11636-131 \quad 11636-272$ \\
\hline $13 \operatorname{Jan} 82$ & 8 \\
\hline $28 \operatorname{Jan} 82$ & \begin{tabular}{|ll}
$2618-317$ & $12619-095$
\end{tabular} \\
\hline $22 \mathrm{Apr} 82$ & 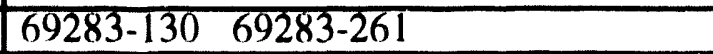 \\
\hline 17 Nov 82 & $\mid 16571-182 \quad 16571-292$ \\
\hline $2 \mathrm{Feb} 83$ & $17240-011 \quad 17240-113$ \\
\hline $18 \mathrm{Mar} 83$ & \begin{tabular}{|ll}
$7891-158$ & $17891-212$ \\
\end{tabular} \\
\hline $22 \mathrm{Apr} 83$ & $18328-242 \quad 18329-005$ \\
\hline $28 \mathrm{Jul} 83$ & $20047-237 \quad 20048-007$ \\
\hline 17 Aug 83 & $20289-328 \quad 20290-045$ \\
\hline $16 \mathrm{Sep} 83$ & $20634-252 \quad 20634-320$ \\
\hline $28 \operatorname{Sep} 83$ & $20873-095 \quad 20873-303$ \\
\hline $8 \mathrm{Dec} 83$ & $22034-181 \quad 22034-328$ \\
\hline $12 \operatorname{Jan} 84$ & $22251-192 \quad 22251-309$ \\
\hline 3 Feb 84 & $22344-065 \quad 22344-115$ \\
\hline $9 \mathrm{Feb} 84$ & $22436-158 \quad 22437-110$ \\
\hline $12 \mathrm{Apr} 84$ & $24207-318 \quad 24208-134$ \\
\hline 30 May 84 & \begin{tabular}{|ll}
$24897-183$ & $24897-246$ \\
\end{tabular} \\
\hline 14 Jun 84 & $25210-245 \quad 25211-023$ \\
\hline $12 \mathrm{Jul} 84$ & $25883-316 \quad 25884-138$ \\
\hline 9 Aug 84 & $26257-048 \quad 26257-186$ \\
\hline $19 \operatorname{Sep} 84$ & $26887-001 \quad 26887-255$ \\
\hline 110 ot 84 & $27170-222 \quad 27171-063$ \\
\hline 8 Nov 84 & $27859-001 \quad 27859-246$ \\
\hline 15 Nov 84 & $27739-216 \quad 27739-289$ \\
\hline 10 Jan 85 & $28658-349 \quad 28659-127$ \\
\hline $14 \mathrm{Feb} 85$ & $29215-239 \quad 29216-016$ \\
\hline 7 Mar 85 & $29565-012 \quad 29565-086$ \\
\hline 11 Apr 85 & $30185-113 \quad 30185-301$ \\
\hline 16 May 85 & $30675-078 \quad 30675-253$ \\
\hline
\end{tabular}

7 A total of 78 Advisory Panel meetings were held. NRC staff has identified 73 panel meeting dates. Transcripts of 67 of the meetings are on the U.S. NRC NUDOCs microfiche system. Individual microfiche are available at all U.S. NRC local public document rooms as well as the public document room located at the Gelman Building, 2120) L Street NW, Washington, D.C. $20(0) 37$.

8 Microfiche location not available. 


\begin{tabular}{|c|c|}
\hline MEETING DATE & MICROFICHELOCATOR NUMBER \\
\hline 20 Jun 85 & $31297-001 \quad 31297-066$ \\
\hline 18 Jul 85 & $32035-289 \quad 32036-067$ \\
\hline $11 \operatorname{Sep} 85$ & $32734-297 \quad 32735-136$ \\
\hline 160 ct 85 & $33230-186 \quad 33230-322$ \\
\hline 19Nov 85 & $33646-046 \quad 33646-101$ \\
\hline $12 \operatorname{Dec} 85$ & $34263-130 \quad 34264-016$ \\
\hline $12 \mathrm{Feb} 86$ & $34640-139 \quad 34640-254$ \\
\hline $10 \mathrm{Apr} 85$ & $35572-048 \quad 35572-161$ \\
\hline 11 Jun 86 & \begin{tabular}{|ll}
$36683-263$ & $36683-337$ \\
\end{tabular} \\
\hline 13 Aug 86 & \begin{tabular}{|l|l|}
8 & \\
\end{tabular} \\
\hline $80 \mathrm{Oct} 86$ & \begin{tabular}{|ll}
$8343-196$ & $38343-335$ \\
\end{tabular} \\
\hline 10 Dec 86 & $39170-197 \quad 39170-330$ \\
\hline $21 \operatorname{Jan} 87$ & $39675-001 \quad 39675-157$ \\
\hline $26 \mathrm{Feb} 87$ & \begin{tabular}{|l|}
$39975-254 \quad 39976-079$ \\
\end{tabular} \\
\hline $25 \operatorname{Mar} 87$ & 8 \\
\hline 16 Apr 87 & $40673-256 \quad 40673-312$ \\
\hline 10 Jun 87 & 8 \\
\hline 12 Aug 87 & $771863-143 \quad 71863-254$ \\
\hline $13 \operatorname{Jan} 88$ & 8 \\
\hline $14 \mathrm{Apr} 88$ & $45715-190 \quad 45715-359$ \\
\hline 26 May 88 & $45970-026 \quad 45970-170$ \\
\hline $14 \mathrm{Jul} 88$ & $46309-144 \quad 46309-317$ \\
\hline 7 Sep 88 & $46850-009 \quad 46850-120$ \\
\hline 25 Oct 88 & \begin{tabular}{|lll}
$47493-324$ & $47493-358$ \\
\end{tabular} \\
\hline $16 \mathrm{Feb} 89$ & \begin{tabular}{|lll}
$48778-218$ & $48778-354$ \\
\end{tabular} \\
\hline 13 Apr 89 & $49632-033 \quad 49632-150$ \\
\hline $21 \operatorname{Sep} 89$ & $51568-001 \quad 51568-181$ \\
\hline $14 \operatorname{Mar} 90$ & $53548-205 \quad 53548-299$ \\
\hline 18 Oct 90 & \begin{tabular}{|l|l|}
$56057-237$ & $56058-031$ \\
\end{tabular} \\
\hline 15 Jan 91 & \begin{tabular}{|ll}
$57223-143$ & $57223-228$ \\
\end{tabular} \\
\hline 16 Apr 92 & $71302-174 \quad 71302-361$ \\
\hline 9 Jun 92 & $62337-202 \quad 62337-336$ \\
\hline $1 \operatorname{Dec} 92$ & $64128-050 \quad 64128-104$ \\
\hline $23 \operatorname{Sep} 93$ & $77168-210 \quad 77169-094$ \\
\hline
\end{tabular}




\section{Appendix B}

\section{Interview protocol}

\section{Introduction}

Introduce yourself to the respondent. Describe the Battelle Human Affairs Research Centers. Explain the goals if the project and how the results will be used. Remind the respondent that the interview is voluntary. Discuss the mechanics of the interview including how it is laid out, how long it will take, taking notes.

\section{Questions for All Respondents}

Questions about the respondents' relationship with the Advisory Panel

- How long have you been involved with Advisory Panel activities?

- How are you [or how have you been] involved with the activities of the TMI-2 Advisory Panel?

- What types of Advisory Panel activities have your participated in?

- Have these activities changed in the last 12 years? How?

- How often do you attend Advisory Panel meetings? Has this changed over the years?

Questions about the Objectives of the Advisory Panel

- Right after the accident at TMI, what did you think was needed to ensure communication umong the public, the licensee, and the NRC?

- Did the Advisory Panel meet those needs?

- What were the Panel's original objectives?

- Do you remember ever seeing those objectives in writing?

- Were the objectives talked about explicitly during any of the Advisory Panel meetings you attended?

- Have the original objectives of the Panel changed? In what ways?

- Do you think the Advisory Panel met its general objectives? How about any objectives that emerged over time?

Questions about the Mechanics of Panel Meetings

- Please describe the "mechanics" of Panel meetings. How are meetings organized and run?

- How are meeting agendas set? Who decides what topics will be covered at each meeting?

- How did the chair come to be selected? Were there criteria for selecting a chair?

- Who typically attended Panel meetings?

- How did someone address the Panel if they had a question or comment? How does a citizen have input?

- Were resolutions or "motions" ever developed and/or voted on? If so, how was this done?

- Did any of the "mechanics" of the Panel change over the years you were involved with the Panel? In what ways? 
Appendix B

- Do you have any idea why the mechanics may have changed?

- Do you think the changes benefited Panel operations?

- Are there particular processes or ways of operating that seem to encourage participation? Can you provide an example?

- Are there particular processes or ways of operating that seem to discourage participation? Can you provide an example?

- Do you have any suggestions for ways to improve the Panel meetings?

Questions about communications between the Advisory Panel and other participants

- How does the Advisory Panel receive information from other parties such as the NRC staff, licensee staff, and members of the public?

- Have these methods changed in the last 12 years? How?

- How does the Advisory Panel communicate information to other parties such as the NRC staff, licensee staff, and members of the public?

- Have these methods changed in the last 12 years? How?

Questions about issues typically addressed during Panel meetings

- What types of issues did the Panel initially address? Were these issues usually resolved? What types of issues was the Panel unable to resolve?

- What types of issues emerged during later years?

- Are there issues that the Panel never addressed? Can you provide examples of issues you believe the Panel should have addressed?

Questions about the nature of the relationship between the parties

- How would you characterize the relationships among the various parties before the accident at TMI-2?

- What can you tell me about the relationships between the various parties after the emergency simmered down but within a month or two of the accident?

- How would you characterize the current relationships among the various parties?

- Did the Advisory Panel play any part in creating or sustaining the relationships you've just described? Can you provide examples?

Questions about the effectiveness of the Advisory Panel

- Do you have any ideas about ways to make the Panel operations more effective?

- Is there some characteristic unique to the TMI-2 cleanup that lends itself particularly well to the use of an advisory group?

- Do you think there is a more appropriate forum for dealing with the issues addressed by the Advisory Panel? What is it?

- Have you ever used a public forum besides the Advisory Panel for addressing issues related to the TMI-2 cleanup? What are those forums?

- Knowing what you know now, do you think the Advisory Panel was an effective forum for dealing with issues related to the TMI-2 cleanup? 
Appendix B

\section{Questions for Specific Groups}

Questions for NRC Staff

- How is the Advisory Panel managed? How is it coordinated with other NRC activities and groups?

- Does the manager responsible for the Advisory Panel have enough authority to help the panel meet its objectives and responsibilities?

- How much time do you think is necessary to effectively manage the Panel?

- How is information from the Advisory Panel used by the NRC? Who uses the information?

- Is there internal criticism of the information received from the Panel? What kinds of criticism are received?

Questions for Panel Members

- How and why did you originally get involved with the Panel?

- Why do you continue to participate in the Panel? (Or alternatively, why did you decide to discontinue participation on the Panel?)

- What value has the Advisory Panel had for you personally?

- What value has the Advisory Panel had for the more general community?

Questions for Media Representatives

- How do you cover Panel activities? What is the focus of any coverage? Has there been any change in type or amount of the coverage?

Thank you for your assistance. What questions do you have for me? 


\section{Appendix C}

List Of Interviewees And Contact Documents

COMPLETED INTERVIEWS

\begin{tabular}{|c|c|c|}
\hline Affiliation & Past Participant & Current Participant \\
\hline Advisory Panel Members & $\begin{array}{l}\text { Dr. Thomas Cochran } \\
\text { Mr. Thomas Gerusky } \\
\text { Dr. Henry Wagner } \\
\text { Dr. Neil Wald }\end{array}$ & $\begin{array}{l}\text { Mr. John Luetzelschwab } \\
\text { Ms. Elizabeth Marshall } \\
\text { Mr. Kenneth Miller } \\
\text { Mr. Arthur Morris } \\
\text { Mr. Frederick Rice } \\
\text { Dr. Gordon Robinson } \\
\text { Mr. Joel Roth } \\
\text { Mrs. Ann Trunk }\end{array}$ \\
\hline NRC Staff & $\begin{array}{l}\text { Mr. Lake Barrett } \\
\text { Dr. Bernie Snyder } \\
\text { Dr. William Travers }\end{array}$ & $\begin{array}{l}\text { Dr. Michael Masnik } \\
\text { Mr. Lee Thonus }\end{array}$ \\
\hline Licensee & $\begin{array}{l}\text { Mr. Frank Standerfer } \\
\text { Dr. Robert Friedman }\end{array}$ & Mr. Robert Rogan \\
\hline Members of the Public & Ms. Joyce Corradi & $\begin{array}{l}\text { Ms. Deborah Davenport } \\
\text { Mrs. Beverly Davis } \\
\text { Mr. Eric Epstein } \\
\text { Ms. Kay Pickering }\end{array}$ \\
\hline Media & & Mr. Ad Crable \\
\hline TOTAL & 10 & 16 \\
\hline
\end{tabular}




\title{
Letters
}

\author{
Initial Contact Letter with Potential Study Participants
}

Dear [Panel Member]:

The Nuclear Regulatory Commission (NRC) has contracter-i with Battelle Pacific Northwest Laboratories (PNL) and Battelle Human Affairs Research Centers (HARC) to document the experiences of the TMI-2 Advisory Panel for the decontamination of Three Mile Island Unit 2 and describe the "lessons learned" by the Advisory Panel experience. To do this analysis, the contractor will be looking at transcripts of the Panel meetings as well as conducting face-to-face and telephone interviews with individuals who participated in Advisory Panel meetings. They will be conducting interviews with a sample of NRC staff, licensee staff, Advisory Panel members, and public and media representatives who participated in Panel activities over the years.

Your membership on the Advisory Panel gives you a special perspective on the Panel's activities and events over the years and your input into the report to the NRC is vital. The contractor will be contacting you to schedule an interview to ask about your experiences on the Advisory Panel. The interview will take approximately 1.5 hours to complete. If possible, a face-to-face interview will be scheduled for a location and time convenient to you. If a face-to-face interview is not possible, the contractor will ask to schedule a phone interview.

The information you provide to HARC interviewers will be critical to providing a meaningful analysis of the Advisory Panel experience over the last twelve years. For this reason, the contractor has been directed to ensure that all interviews are confidential and that all reports from these interviews do not reveal, either implicitly or explicitly, the identity of any interviewee without their explicit permission. The principal investigator on the project, Denise Lach, will be calling you soon to schedule an interview. If you have any questions about the project, please feel free to contact the PNL project manager, Becky Harty at (509) 375-2263, or the HARC project manager, Nancy Durbin, at (206) 528-3248.

Sincerely,

Michael Masnik

NRC Project Manager 
Interview Confirmation Letter

Dear [Interview participant]:

I enjoyed talking with you on the phone last week and am pleased that you agreed to an interview about your experiences with the Three Mile Island Advisory Panel. Either I and/or my colleague, Dr. Trish Bolton and Dr. Nancy Durbin, will be conducting the actual interview. We look forward to meeting you at take about one and a half hours to complete. . The interview should

As Mike Masnik explained in his recent letter, your participation is vital to any understanding of the Advisory Panel experience. All comments you make during the interview will remain strictly confidential unless you give us express permission to attribute a specific quote to you. Your identity will not be revealed, either implicitly or explicitly, in any reports resulting from this study.

If you are unable to make the scheduled interview, please feel free to call me at 206-5283319 before May 5 or at 717-561-1900 after May 9. Thank you.

Sincerely,

Denise H. Lach, Ph.D.

Research Sociologist 
Dear (Interviewee):

Thank you, again, for your participation in the recent interview with Battelle staff members about your experiences with the TMI-2 Advisory Panel. The information and perspective you provided during the interview are vital to a comprehensive review of the Panel over its thirteen year existence.

We asked Battelle to interview current and past members of the Panel and to complement these with interviews of NRC staff members, licensee staff members, members of the public, and media representatives. These interviews are essentially complete. Although the contents of each interview are confidential, Battelle staff let us know that everyone they asked to participate agreed to an interview. The interviewers also felt that everyone was frank and open during the interviews and were particularly impressed with the quality and usefulness of the information they received. We expect the final report to contain valuable information about the Advisory Panel experience.

The final report prepared for the NRC by Battelle will describe the "lessons learned" through the Advisory Panel experience: participants' perceptions of what worked to make the Panel an effective conduit of information, what was less successful in facilitating the exchange of information, and what changes were made along the way to address participants' concerns. The report, which should be ready in early 1994, will be forwarded to you if you requested a copy.

If you have any questions about the interviews or the report, please feel free to contact the Battelle project manager, Nancy Durbin, at (206) 528-3248, or the principal investigator, Denise Lach, at (206) 528-3319. You can also call me at the NRC, toll free, at 1-800-4268096 with any questions.

Sincerely,

Michael Masnik NRC Project Manager 

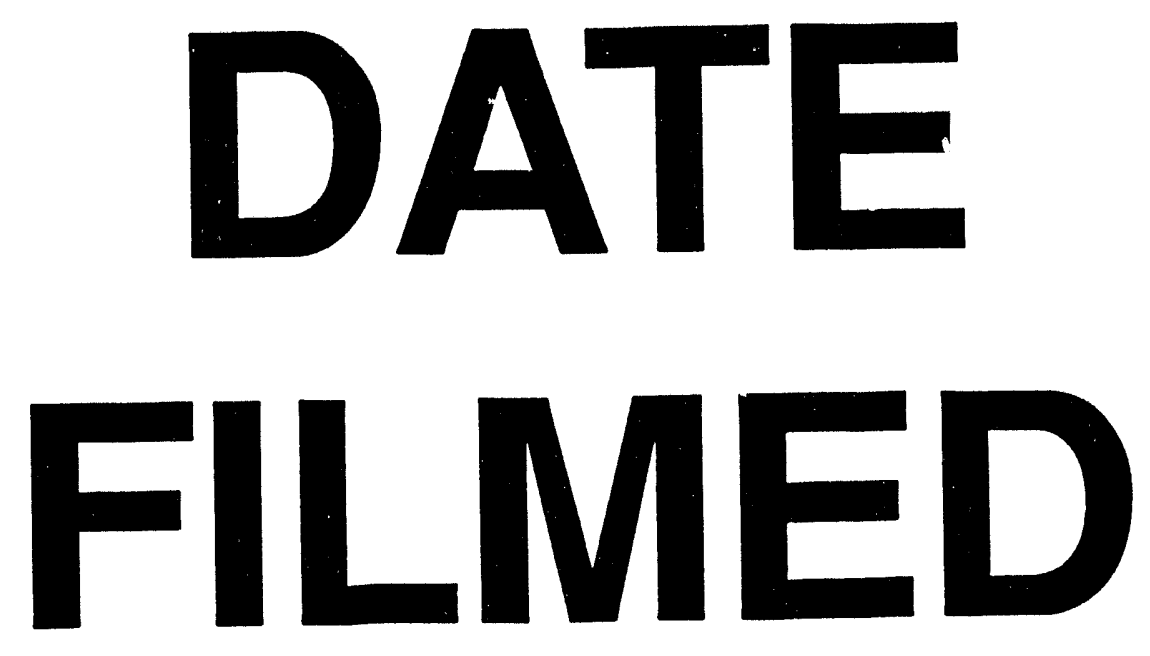

$10 / 24 / 94$
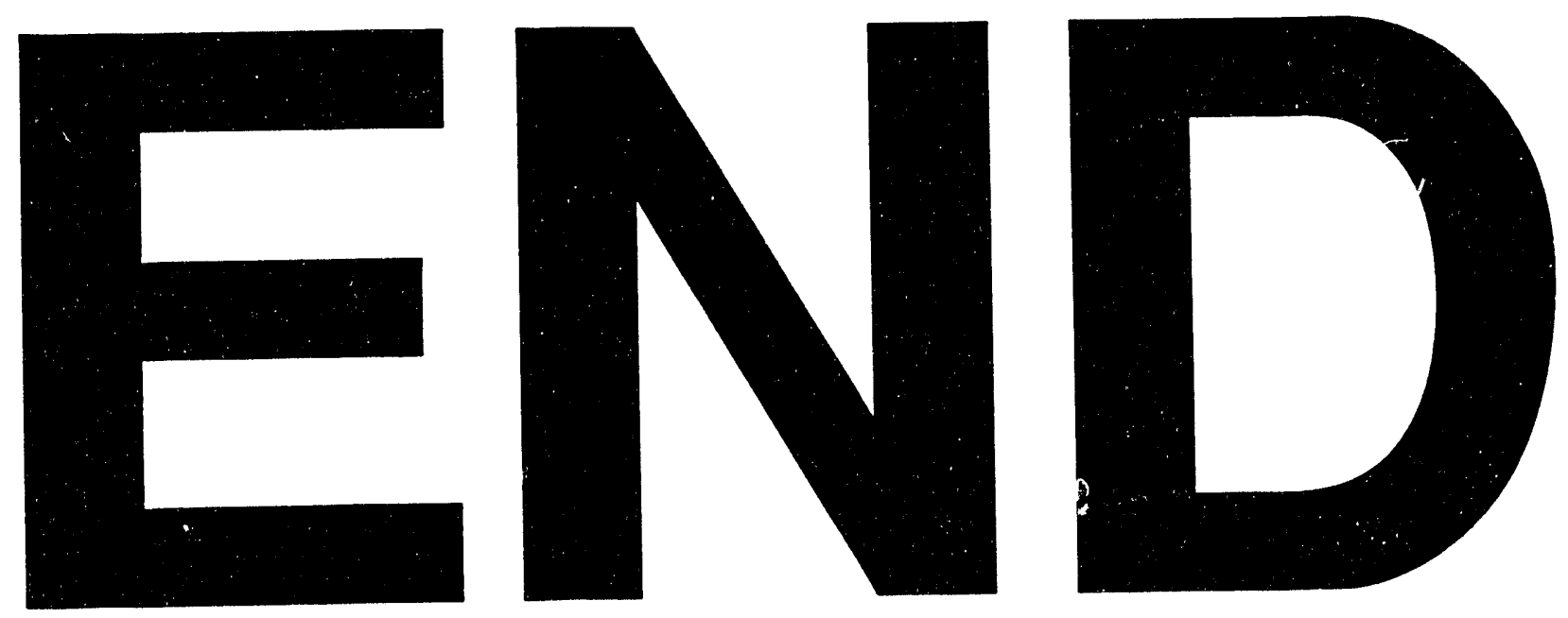


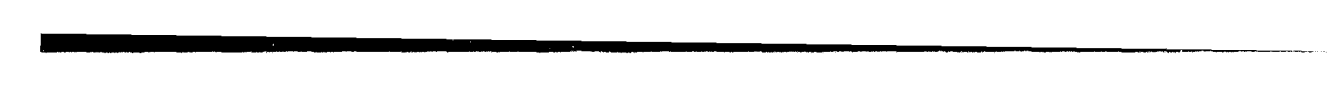

